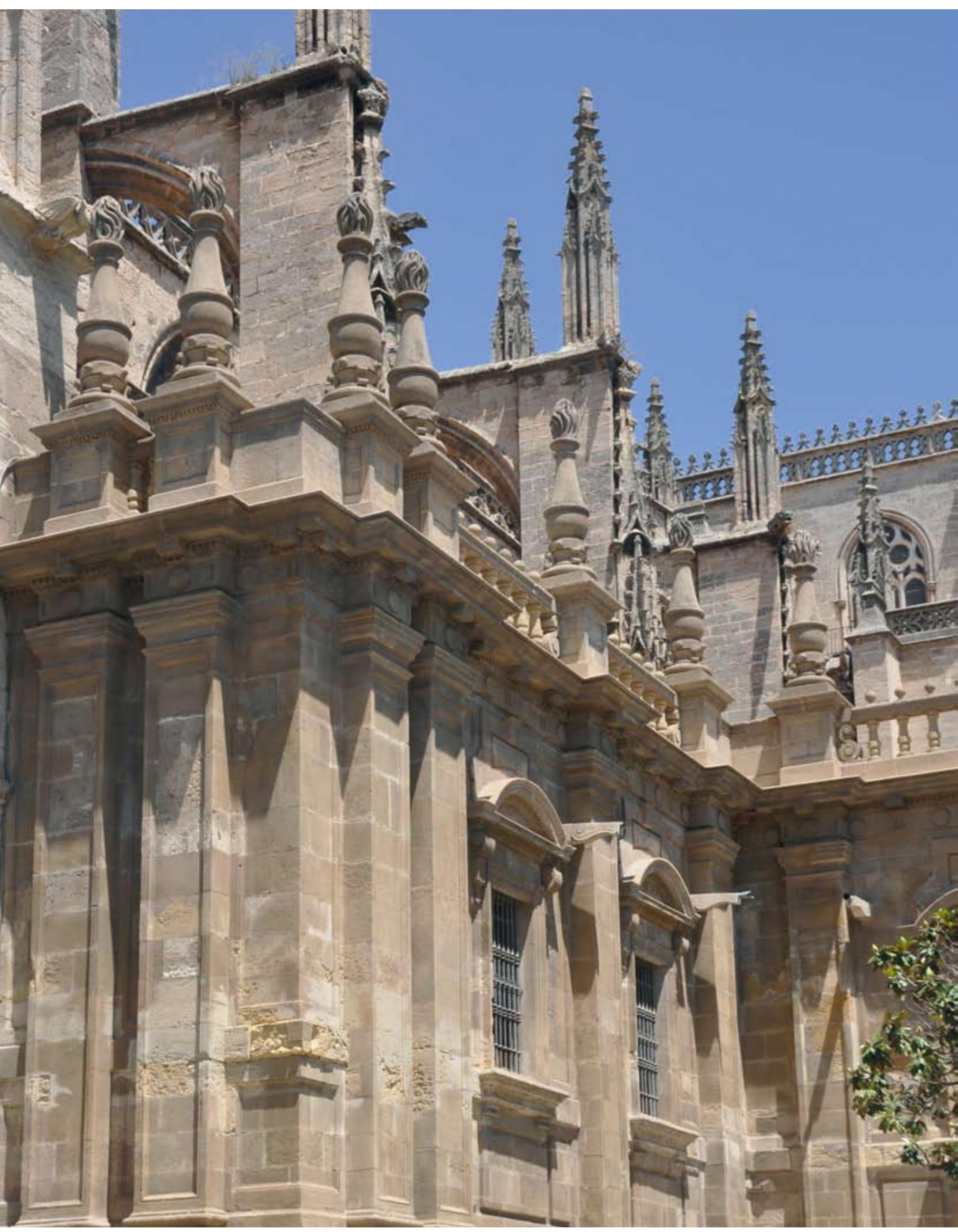




\section{El comportamiento de la piedra de las fachadas del ángulo suroeste de la Catedral de Sevilla tras su restauración}

Maria Gracia Gómez de Terreros Guardiola, Dpto. de Construcciones Arquitectónicas II, Universidad de Sevilla; Carmen Enriquez Díaz, Dpto. de Restauración de Construcciones Bellido

\section{Resumen}

Entre los años 1995-2001 se llevó a cabo una importante restauración de las fachadas de la esquina suroeste de la Catedral de Sevilla, cuya piedra presentaba un grave estado de alteración. Pasados pocos años, el material pétreo volvió a manifestar lesiones que dieron pie a plantear un estudio sobre su comportamiento. El presente artículo describe el trabajo desarrollado, que aborda desde la recogida de cuanta información ha sido posible sobre el edificio, su historia constructiva, estado de alteración previo a la restauración y la intervención misma, hasta el análisis del estado que presentaba la fábrica pocos años después, su comparación con la alteración anterior y el seguimiento de la evolución de las lesiones.

Se han realizado análisis y ensayos que han dado un apoyo científico a las observaciones efectuadas y arrojado cierta luz sobre la eficacia de los tratamientos aplicados y los trabajos ejecutados. De esta forma, se ha determinado la bondad de la restauración realizada y se han generado líneas más claras de actuación para futuras intervenciones.

\section{Palabras clave}

Alteración / Catedral de Sevilla / Conservación / Ensayos de alteración / Estudio / Historia / Intervención / Materiales pétreos / Piedra / Portadas de edificios / Sevilla 


\section{INTRODUCCIÓN}

La construcción del ángulo suroeste de la Catedral de Sevilla es una edificación de apariencia unitaria, con una fachada que presenta una modulación casi regular, constituida por un alto basamento sobre el que se apoya un orden de pilastras, y que se remata potentemente mediante unas cornisas, balaustradas y flameros. Su planta tiene una ordenación cuadriculada constituida por bóvedas de aristas apoyadas en arcos, que dan lugar a espacios independientes, a un gran patio, a un corredor cruzado que comunica con la Catedral, y desde el cual el edificio se quiebra, estrecha, y prolonga hasta los pies del templo, donde genera otro patio y una nueva estancia abovedada.

Es la última construcción que se realizó en la Catedral, y se ejecutó en varias etapas. En 1757 se proyectó un edificio para dependencias de usos varios, y la obra se empezó en 1760. La fachada inicialmente seguía el estilo arquitectónico y la volumetría de la esquina suroeste de la Catedral, con un orden gigante de dos cuerpos. Sólo se construyó el primer cuerpo del muro de fachada, generando el cerramiento, inacabado y sin remate superior, un recinto interior que se fue ocupando según se necesitase. Los materiales empleados fueron piedra para los muros y fábrica de ladrillo para las bóvedas. Hay libramientos de esta época de piedra de las canteras de Morón y Gandul (esta más económica y de peor apariencia). Puede apreciarse un material pétreo diferente en el paramento oeste, que coincide en fechas con demoliciones que se llevaron a cabo de unas casas adosadas en esa zona. Para estancias interiores, hay libramientos de piedra de las canteras de Estepa. En 1805 se realizó una reforma en la que se construyó una bóveda vaída de mayor dimensión y para la que se recreció la fábrica en los paños delanteros a la misma, situados en la zona sureste, con piedra procedente de las canteras de San Cristóbal, en El Puerto de Santa Maria (JIMÉNEZ MARTíN y PINTO PUERTO, 2003: 202).

Entre los años 1913 y 1917 se llevó a cabo una restauración sin modificaciones estéticas significativas, ya que fue debida a que la fábrica presentaba un estado de deterioro muy acusado, en especial en las zonas de basamentos y zócalo en las que se utilizó piedra Novelda. En 1918, el entonces arquitecto del templo, Joaquín de la Concha Alcalde, redactó un proyecto para terminación del pabellón que pretendia igualar sus fachadas con las de la esquina suroeste, elevándola un segundo piso. La solución creó gran polémica y el proyecto no llegó a tramitarse (GÓMEZ DE TERREROS, 1996: 209-234).

Finalmente, en 1921 Francisco Javier de Luque y López, sucesor del anterior arquitecto, redactó un nuevo proyecto para la terminación de la fachada de estas dependencias, que sí se materializó. La solución planteada utilizaba lo construido, reconvirtiendo su composición en una de proporciones más reducidas, rematándolo y dándole al edificio el aspecto unitario que hoy presenta. Se respetaron las dimensiones de los entrepaños y algunos elementos como los ventanales, sus remates y algunas molduras. Pero hubo también modificaciones de importancia: se rebajó y relabró la zona inferior para obtener nuevas formas y se completó la ornamentación superior con la elaboración del entablamento, cornisa, gárgolas, balaustrada y pináculos. El proyecto contiene una información
Alzados originales y alzados reformados del proyecto de terminación de la fachada suroeste de la Catedral de Sevilla. Francisco Javier de Luque y López (1921).

Fuente: Ministerio de Cultura, Archivo General de la Administración, IDD (05)

001.003 , caja $31 / 4890$

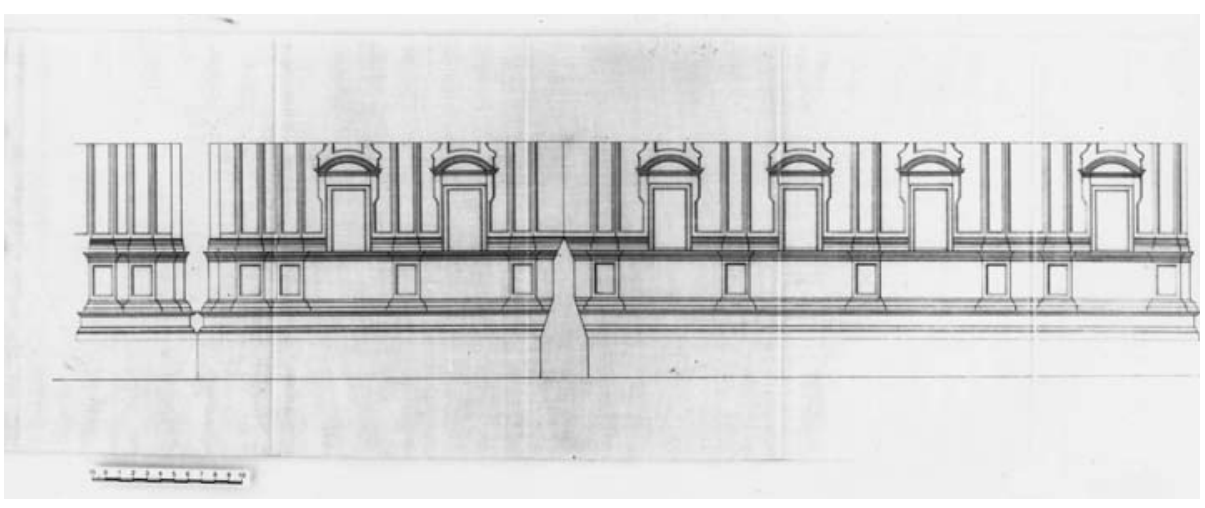


gráfica muy valiosa, de lo preexistente y de lo que se realizó. La terminación de la fachada se resolvió desde una visión puramente estética, sin consideraciones a funciones e interdependencias de elementos constructivos. De esta forma, la situación de la cubierta preexistente quedó muy por debajo de la línea de cornisa.

En el proyecto se indica que los sillares que se sustituyesen y los de nueva aportación serian de piedras procedentes de las canteras de El Puerto de Santa María y que la elección de dichas canteras se condicionaba al origen del material pétreo existente en la edificación. Existen facturas de obras realizadas del año 1924-25 donde constan recibos de piedra de sillería franca de El Puerto de Santa María; otras de febrero de 1925, de piedra de sillería de Monovar y seis bolas de martelilla; y otro recibo de abril de 1925 de siete bolas y siete balaustres de piedra martelilla (GÓMEZ DE TERREROS, 1993: 250). A partir de todos estos datos históricos, se concluye que la unidad formal de la edificación no se corresponde ni con la uniformidad en los materiales pétreos y en los de rejuntado empleados (cemento Pórtland incluido en los primeros años del siglo XX), ni con una construcción unitaria, lo cual podrá justificar determinadas localizaciones de daños.

\section{DATOS PREVIOS SOBRE MATERIALES PÉTREOS Y PRODUCTOS DE TRATAMIENTO}

La piedra de la Catedral de Sevilla, su caracterización y el establecimiento de su grado de alteración fue objeto de varias investigaciones llevadas a cabo en los años ochenta y publicaciones rea- lizadas entre los años 1984 y 1990 (ALCADE, 1990: 5-28; BELLO, 1988; ESBERT, 1988: 5-23). Los estudios indicaban que la mayor parte de la piedra constitutiva de la Catedral es una biocalcarenita (caliza fosilifera), de textura granuda, con grano generalmente grueso y abundantes fósiles, de color amarillento en cantera, pero que mostraba variaciones de aspecto y coloración en la superficie del monumento. Existen otros tipos de piedra, entre los que se destacan uno de grano grueso y restos de algas; y otro de grano más fino y que contiene bioclastos y granos de cuarzo.

Varios aspectos destacan de los indicadores de alteración que presentaba la piedra de esta zona de la Catedral. La superficie de la piedra aparecía con una costra de tonalidad grisácea, que se mostraba muy oscurecida en las zonas bajas y en las de cornisas. Existian biocostras y algunas plantas superiores asociadas a zonas húmedas, y eflorescencias en las zonas bajo las cornisas y en juntas de sillares que constituyen las molduras existentes bajo los grandes huecos. Destacaban las diferentes decohesiones que se producian: unas se acompañaban de arenizaciones generalizadas, mientras otras producian lesiones muy irregularmente repartidas. También se localizaron picados en los paramentos más expuestos y alveolizaciones, estas últimas en los zócalos y en piedras de coloración amarillenta más acentuada. Finalmente, se localizaron excoriaciones y estriados no muy extendidos.

También se realizaron en los años noventa investigaciones sobre varios tratamientos de hidrofugación aplicados en distintos tipos de piedra, que fueron publicados en los años 91-93 (VILLEGAS, 1991: 19-12; 1993: 5-13 y 25-37), entre ellas calizas fosiliferas de
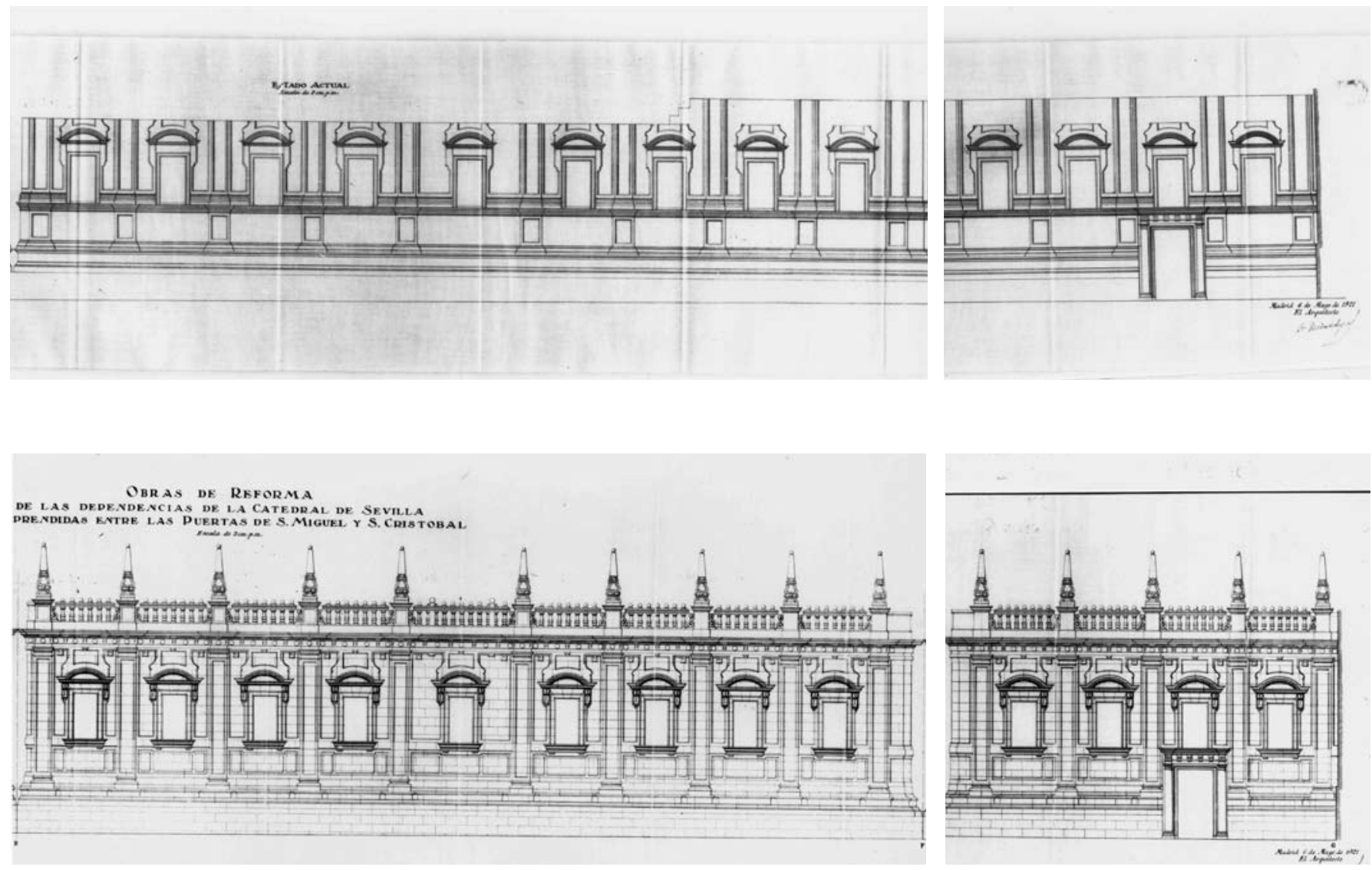
El Puerto de Santa Maria y de Espera, y en los que realizaron ensayos de comportamiento frente a la acción del agua, y acelerados de los tipos de cristalización de sales y exposición a ambientes contaminados. Las experiencias permitieron apreciar la alteración natural de estos tipos de piedras, sus diferencias y comparar, además, los resultados de la piedra sin tratar con los distintos tratamientos aplicados a las mismas.

Estas investigaciones determinaron cómo la alteración natural de la piedra de El Puerto de Santa María sometida a contaminación se produce de una forma homogénea en toda la superficie y se manifiesta en la formación de una costra superficial de sulfatos. Al contar con tamaño de poros grandes, las tensiones de cristalización de sales pueden ser absorbidas, retardando la aparición de la alteración macroscópica, y comenzando ésta con la aparición de ligeras fisuras en vértices y aristas. En el ensayo de cristalización de sales, la alteración se manifiesta por la caída de partículas que se produce de una forma homogénea en la superficie y que, por tanto, redondea vértices y aristas. La piedra de Espera presenta mayor indice de huecos pequeños, distribuidos irregularmente, y es mucho más alterable frente a la contaminación. En las zonas más porosas aparecen importantes fisuras y disyunciones, mientras que en las de menor porosidad aparecen eflorescencias. También aparecen algunas ampollas. En el ensayo de cristalización de sales el desprendimiento de material se produce irregularmente, generando distintas formaciones de huecos en superficie, aunque manteniendo en algunos casos aristas y vértices.

Entre los tratamientos ensayados se encontraba el Tegosivin HL100, que se ha empleado en la intervención. Tras los ensayos en atmósferas contaminadas se concluyó, para la piedra de El Puerto de Santa Maria, que todos los tratamientos mejoran su comportamiento. En este mismo ensayo y, el caso de la piedra de Espera, no se observa mejoría, al disminuir el tamaño de poros, y generan eflorescencias, empollas, figuraciones y disyunciones. En el ensayo de cristalización de sales, los productos organosilícicos mejoran el comportamiento de ambos tipos de piedra, en el sentido de que no lo alteran, pero lo retrasan en el tiempo.

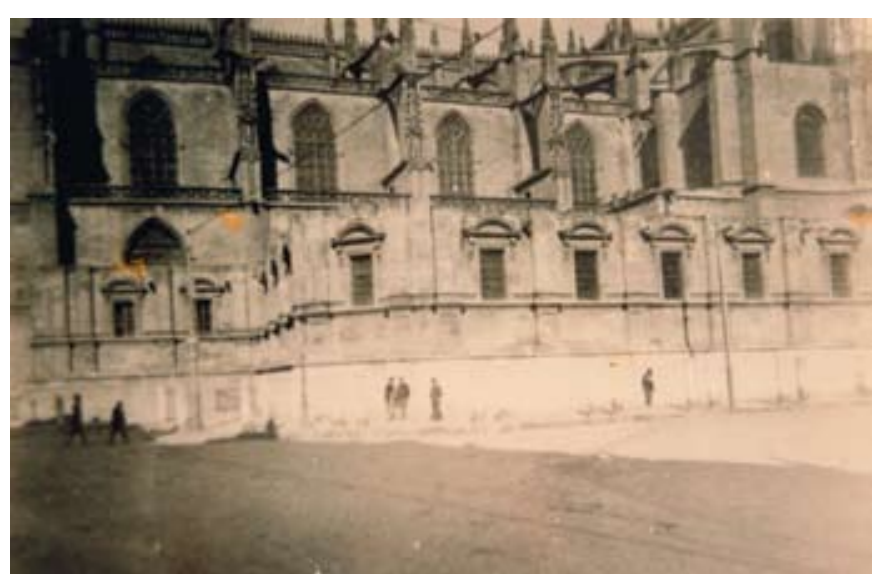

Aspecto que presentaba la fachada suroeste de la Catedral anterior a la intervención de F. J. Luque y López. Fuente: Ministerio de Cultura, Archivo Genera de la Administración, IDD (05) 001.003 , caja 31 / 4890

\section{INTERVENCIÓN REALIZADA (1995-2001)}

La obtención de información sobre el proyecto y la intervención llevada a cabo por los arquitectos Francisco Pinto Puerto y Miguel Ángel Som Ruiz fue autorizada por el Cabildo Catedraliceo y el arquitecto conservador de la Catedral Alfonso Jiménez Martín, y ha sido facilitada por Francisco Pinto Puerto, y por algunos de los restauradores que intervinieron en las mismas. Sus descripciones sobre las distintas fases de la intervención, ensayos, medidas y soluciones adoptadas, junto con la información fotográfica facilitada, resultan muy reveladoras.

La intervención sobre la fachada se ha llevado a cabo entre los años 1995-2001, y formaba parte de una intervención de restauración del edificio para adaptarlo a nuevas necesidades de la Catedral. El trabajo fue realizado por un equipo interdisciplinar y con experiencia en el campo de la restauración arquitectónica. En lo que respecta a la fábrica, se plantearon dos fases consecutivas: la primera, consistente en una completa auscultación y diagnóstico; y la segunda de la restauración propiamente dicha. Existe una tercera fase, de simple acabado o terminación, que coincide con la terminación de las obras interiores del edificio.

\section{Primera fase: auscultación, análisis y diagnósticos realizados}

La fase primera se desarrolló durante los años 1995 y 1997 y recogió toda la información disponible del edificio, buscando establecer límites y posibilidades de intervención. Se realizó un levantamiento, sobre el que se desarrolló un primer análisis del edificio, que recogía los estados de conservación de sus elementos y los procesos constructivos observables a través de su forma y su fábrica. Este levantamiento dio respuesta a algunas cuestiones constructivas y a ciertas lesiones, y permitía relacionar aspectos que parecian anteriormente sin conexión. El levantamiento se cumplimentó con unos mapeos de los daños que presentaban las fachadas. Éstos se manifestaban de forma generalizada, y se agruparon en dos tipos muy diferentes aunque íntimamente relacionados: las humedades y las pérdidas de material. Las primeras se dividieron entre las de filtración y de capilaridad, mientras que las segundas presentaban manifestaciones e intensidades muy variadas y se clasificaron como pérdida en volumen de material, pérdida superficial, pérdida de mortero y exfoliación.

Una vez establecida la localización de las lesiones, se decidió cómo y dónde realizar la toma de muestras, y se previeron los ensayos a llevar a cabo, de una forma racional y coherente con el proceso constructivo del edificio y con los medios disponibles. Los ensayos los realizó la empresa Geocisa. Se escogieron cuatro puntos de ensayo, en los que se tomaron muestras de los paramentos en tres bandas o alturas: la baja, constituida por el zócalo; la intermedia, desde la anterior a la línea de la primera etapa constructiva; y la alta, coincidente con el remate de 1921. Todas las muestras se tomaron con máquina saca testigo y por personal especializado, que 


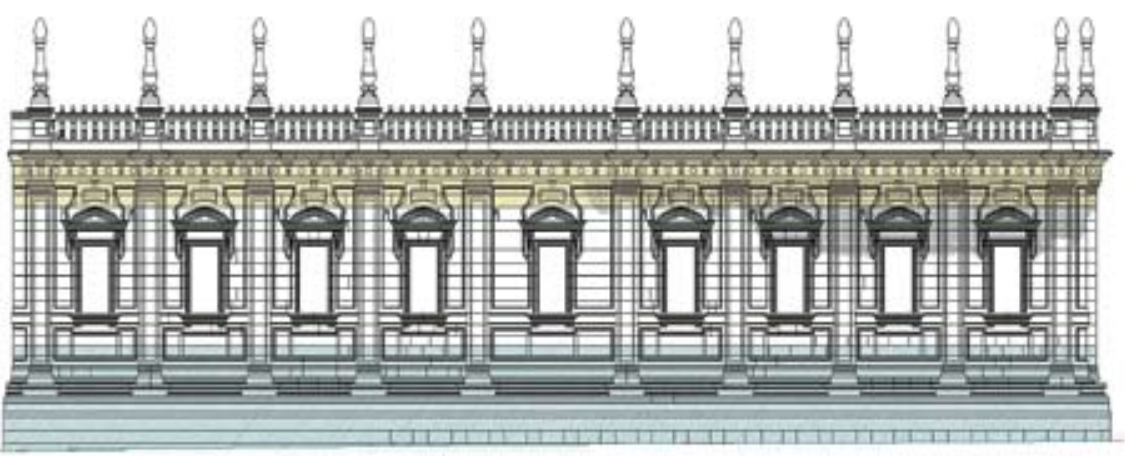

Nitico 98 maxh ?

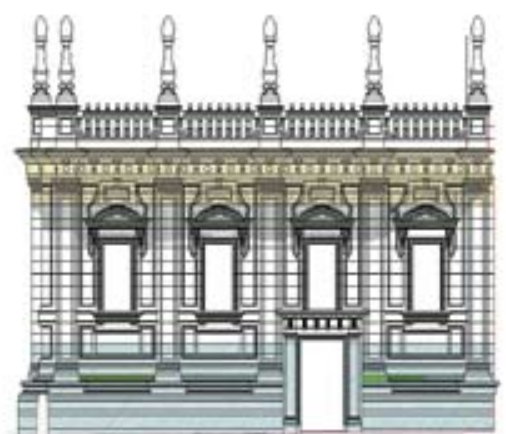

NZWOOERA

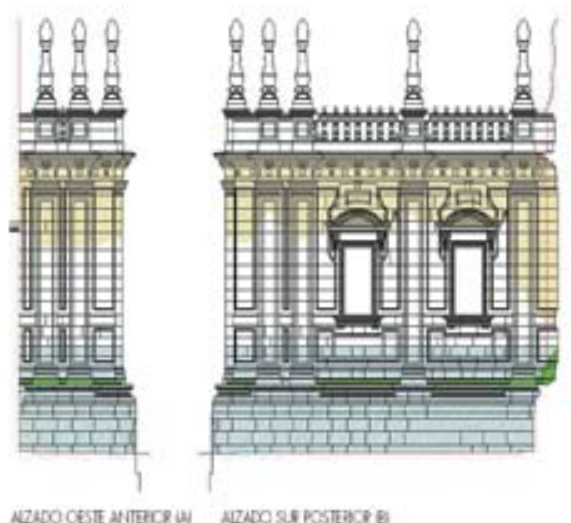

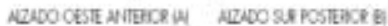

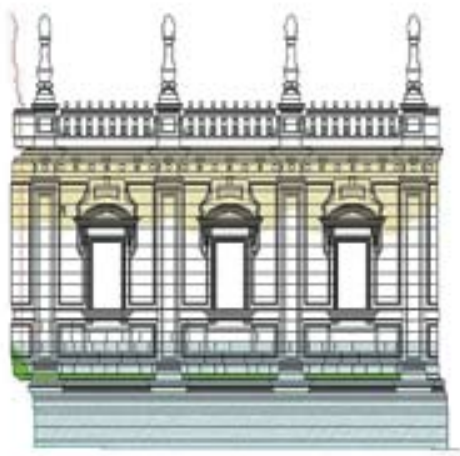

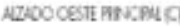

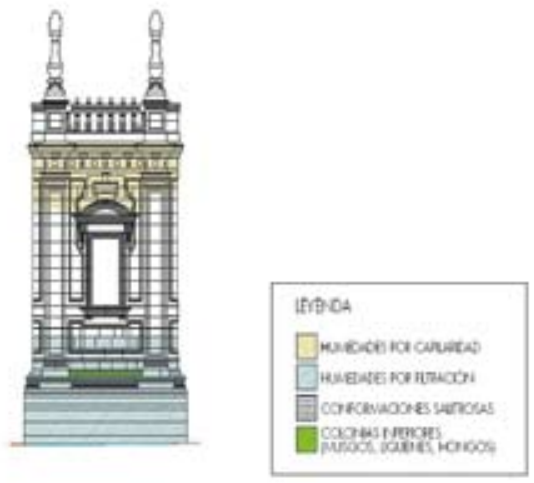

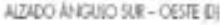

MAPA DE HUMEDADES, ESTADO DE FFOVECTO

Mapa de humedades. Estado previo a la intervención. Proyecto de rehabilitación de Pabellón para Exposición y Recepción. I Fase. Campaña de auscultación y consolidación parietal. Francisco Pinto Prieto y Miguel Ángel Som Ruiz, 1997. Fuente: Representación elaborada a partir de la planimetría facilitada por Francisco Pinto Puerto
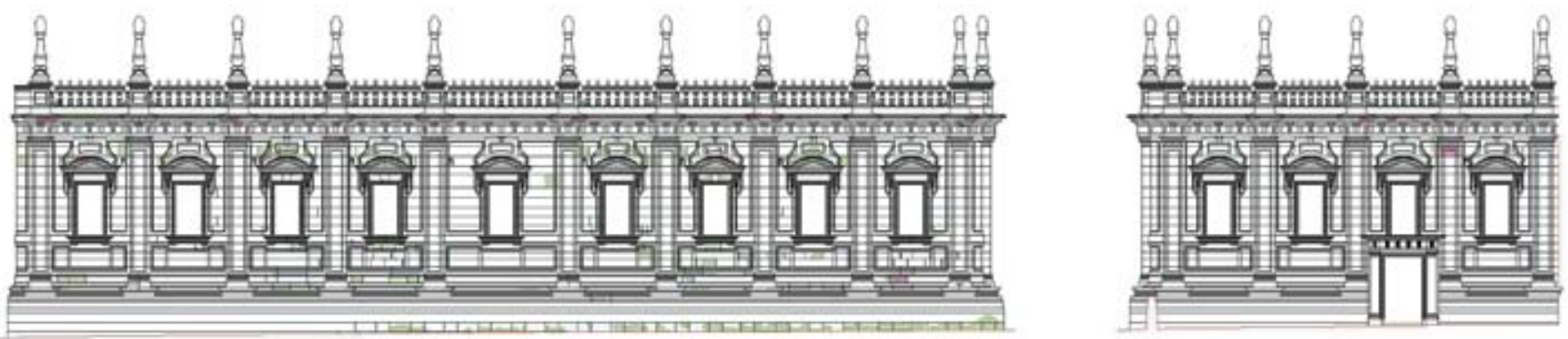

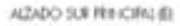
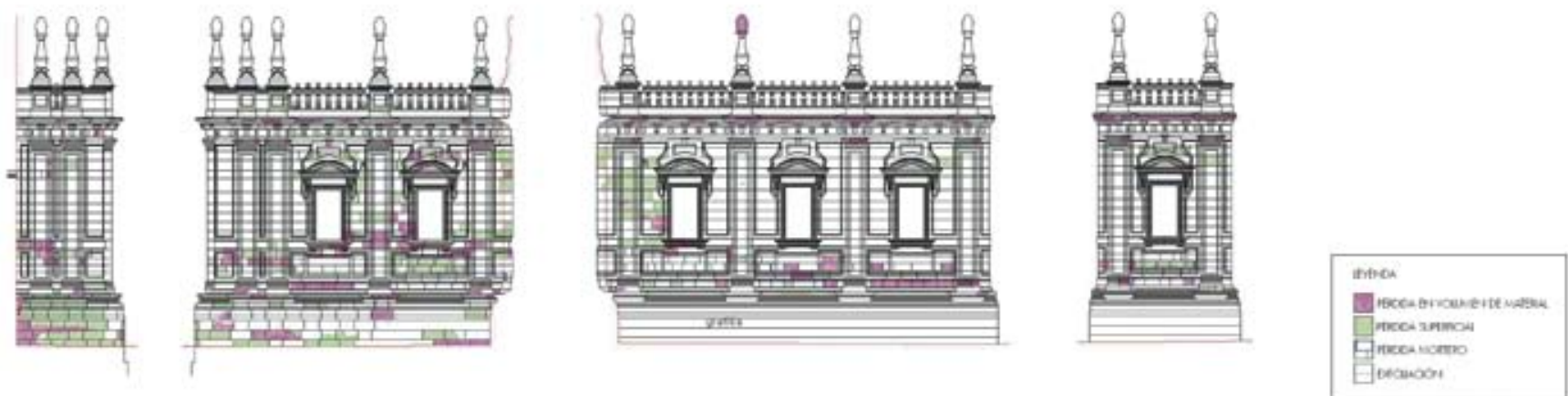

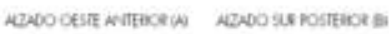

NOWO CES HiCRN IO

NCHO HOHOSE - CEIEO

MAPA DE DETERIOROS APARENTES Y PÉRDIDAS DE MATEPIAL ESTADO DE PAOYECTO

Mapa de deterioros aparentes y pérdida de material. Estado previo a la intervención. Proyecto de Rehabilitación de Pabellón para Exposición y Recepción. I Fase.

Campaña de auscultación y consolidación parietal. Francisco Pinto Puerto y Miguel Ángel Som Ruiz, 1997. Fuente: Representación elaborada a partir de la planimetría facilitada por Francisco Pinto Puerto 

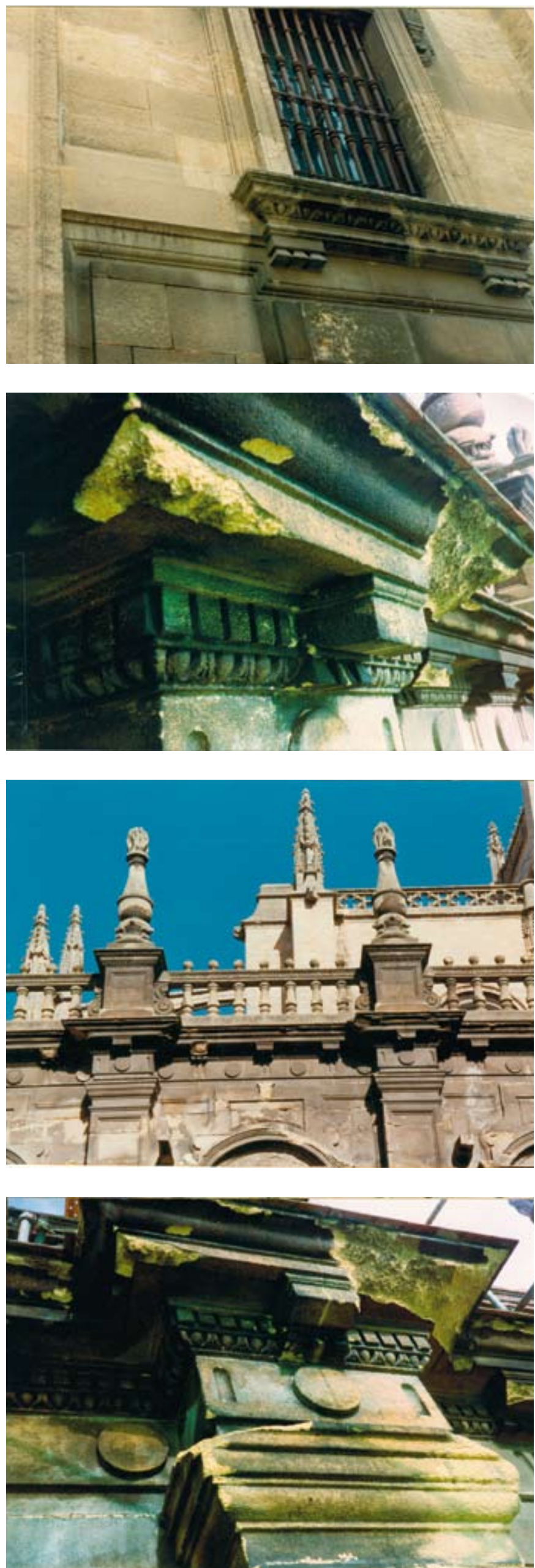

Detalles de zonas con pérdidas de volúmenes decorativos. Estado previo a la intervención 1993-1996. Fotos: Francisco Pinto Puerto las encapsularon para su conservación en estado natural, hasta la realización de ensayos en laboratorio.

En el laboratorio se caracterizaron las piedras que forman la sillería actual y se realizaron determinaciones de humedad, densidad aparente, porosidad, resistencia a compresión en estado seco y saturado, resistencia a corte, módulo de deformación longitudinal, clasificación litológica, y análisis químico a los morteros para determinar su composición, con identificación y clasificación de las alteraciones en los materiales, incluyendo su composición mediante análisis y su observación al microscopio.

Los análisis permitieron caracterizar tres tipos de piedra empleados en la fachada. El primero es una caliza de color gris claro (localizada en zonas bajas de las fachadas oeste trasera, sur y este), que se describe como una roca compacta, con aloquimicos constituidos por fósiles, intraclastos de micrita y cuarzo, intimamente unidos a cemento de esparita no muy abundante, formando una especie de mosaico y que se clasifica como bio o intra esparita arenosa. Un segundo tipo lo constituye una arenisca de color anaranjado pálido (localizada en parte baja de la fachada oeste delantera, y zonas bajas y altas de esta fachada anterior, la sur y la este), que se describe como bastante deleznable y de grano grueso, con esqueleto de conchas, fósiles (45\%) y cuarzo (55\%) y cemento de esparita bastante escaso, y que se clasifica como una calcarenita. El tercer tipo es una caliza compacta arenosa de granos tanto finos como gruesos (localizada en zona baja de la fachada oeste delantera y media de la fachada este), que se describe con aloquímicos fósiles, intraclastos de micrita y escaso cuarzo, y escasa matriz micritica, y que se clasifica como bio intra micritica arenosa. Se caracterizó otra cuarta piedra pero, al localizarse en el interior del muro este, no se consideró.

También se analizaron cuatro tipos de piedra de similares características localizadas en canteras del entorno, en previsión de que tuvieran que ser sustituidos sillares especialmente deteriorados, buscando la similitud en apariencia y en propiedades petrofísicas. Una de ellas parecía ser de la misma cantera que la caliza primera descrita. Otra parecia bastante similar a las muestras sanas de calcarenita. Los otros dos tipos son similares al tipo de piedra no descrito, por localizarse en el interior del edificio.

Se caracterizaron los morteros existentes en la fábrica, con técnicas de microscopía petrográfica y difracción de rayos $X_{i}$ se estudiaron los morteros de cal y de restauración Naturstein, realizándose probetas que comprobaron el comportamiento hidrico de ambos, antes y después del tratamiento con productos; y se ensayó la adherencia mortero-piedra, sometiéndola a ciclos de envejecimiento acelerado. Se realizaron ensayos para la determinación de la permeabilidad al vapor de las muestras, buscando dar una propuesta de tratamientos consolidantes, y/o hidrofugantes, con diferentes productos, determinando la acción de los mismos, la proporción a utilizar y el método de aplicación. Estos ensayos se realizaron en laboratorio e in situ, y buscaban determinar la capacidad de 
absorción de agua de lluvia de las distintas piedras de la fachada. Se utilizó el método de la pipeta, como ensayo in situ, y se realizó antes y después del tratamiento, para comprobar su eficacia.

Finalmente se estudió la humedad en los muros, tomando medidas en las zonas marcadas en los planos y dejando marcas indelebles para posteriores mediciones. Las medidas se realizaron con el método directo protimeter y se contrastaron con los datos de humedad que se tomaron mediante el método de la estufa. Esta primera fase de intervención permitió cuantificar la superficie sobre la que actuar, considerar los trabajos a realizar y ordenarlos estratégicamente.

\section{Segunda fase: intervención sobre la fábrica}

La segunda fase fue de restauración propiamente dicha y se llevó a cabo entre los años 1998 y 1999. Se inició con una auscultación más profunda y continuó con operaciones de limpieza, restitución, consolidación y protección. La intervención la llevó a cabo la empresa Joaquín Pérez S.A.

La verdadera auscultación se realizó conjuntamente con la limpieza superficial, que se realizó con agua y cepillo de raices, y que eliminaba la primera capa de suciedad, dejando a la vista nuevas texturas y daños. Era una observación muy directa, realizada desde andamiajes, que permitió apreciar mejor las lesiones y deterioros. Se actuó por módulos y, simultáneamente, se elaboraron unas fichas de lesiones a mayor escala, que se convirtieron en un documento clave del proceso de intervención diseñado, de tal forma que se iba completando el mapa de pérdidas de material, y obteniendo un plan de actuación más concreto y cierto. Durante la limpieza aparecieron piedras muy disgregadas, parte de las cuales se sujetaba exclusivamente por la espesa costra superficial, y cuyo desprendimiento constituía un serio peligro potencial. Los elementos más afectados por pérdidas de material estaban localizados, de forma general, en los remates superiores de la fachada y en algunos sillares de la zona intermedia, fundamentalmente en las fachadas de los paramentos más cercanos a la avenida de la Constitución.

La profunda auscultación llevada a cabo junto con los resultados de los ensayos realizados dieron pie a poder ofrecer un abanico de tratamientos y actuaciones a llevar a cabo, aplicado con gran precisión, de tal forma que permitieron definir los tratamientos específicos a realizar sobre cada sillar de la fábrica. El proceso concretó productos y métodos de aplicación, evitando tratamientos genéricos de mayor coste en tiempo y económico. En el estudio de la evolución posterior, este documento tendrá gran valor.

A partir del nuevo mapping de alteraciones, se inició el proceso de restauración propiamente dicho. De forma generalizada, donde la suciedad no se eliminó con el cepillado, se utilizó la limpieza con microesferas (métodos físicos más especializados) ya que es un método inocuo y de fácil aplicación in situ. En superficies muy ennegrecidas, como la zona de cornisas, y donde el espesor y forma de la costra lo permitía, se realizó una limpieza química con papetas de AB57.
Simultáneamente a la limpieza se realizaron restituciones, que consistieron bien en sustituciones parciales de sillares con piedra natural, bien en reintegraciones de volúmenes con mortero pétreo de reposición. El criterio de intervención se ajustó a evidentes principios de seguridad y de estética. La fachada cuenta con la ventaja de tener una estética global y repetitiva, y de no contar con elementos de gran valor figurativo o singular. En los casos en que la pérdida de material era importante, tanto como para hacer peligrar la estabilidad del elemento o sus adyacentes, o el sentido arquitectónico del sector, se restituyeron las superficies originales. Los sillares más afectados (cornisas y zona intermedia) fueron seleccionados con prudencia. Parte de los mismos se sustituyó por otros sillares labrados con su mismo formato y molduración. El material que se utilizó para estas restituciones fue una de las piedras de cantera ensayada, que contaba con las caracteristicas petrográficas más próximas a la del monumento, lo que garantizaba cierta homogeneidad y compatibilidad. El material escogido era una calcarenita muy similar, pero más resistente, que permitía de alguna manera garantizar la adecuada reserva de autenticidad del conjunto; procedía de Almería, y se identificaba como de las canteras de Pedrera.

Se optó por la utilización de material pétreo artificial para resolver temas puntuales y menos gravosos, como terminaciones miméticas y recuperación de linealidades. Las partes restituidas con materiales artificiales fueron aquellas que lo perdido era sustancialmente menor en cuantía que la pieza a la que pertenecia (sillar de moldura, ornamento, zonas puntuales de cornisas, frontones, jambas y alfeizares, etc.). No se reprodujeron completamente los elementos, sólo lo suficiente para permitir la estabilidad ante futuras agresiones y garantizar los valores perceptivos. La elección del mortero de reposición se apoyó en los ensayos realizados y, además de los criterios anteriores y precauciones anteriores, se primó el garantizar la perfecta yuxtaposición y permanente adherencia a las partes originales. El material utilizado fue mortero de restauración de la marca Cumen.

Seguidamente se aplicó a toda la superficie un producto biocida, si bien se incidió sobre las zonas de repisas, de sedimentaciones y de escorrentías. Posteriormente se consolidó toda la fachada con el consolidante Tegovakon, en la cantidad de producto que la piedra admitía (hasta no absorber más). Al producto se le añadieron pigmentos inorgánicos para ir igualando la coloración de la superficie de la fachada. El consolidante se aplicó los meses de febrero-marzo de 1999, sobre una superficie con cierto grado de humedad. Finalmente se hidrofugó con Tegosivin, aplicado éste ya sin pigmentación. Al igual que el consolidante, este producto se aplicó en la cantidad que absorbía la piedra, es decir hasta rechazo. Se concluyó esta fase de actuación con la retirada de los andamios, lo que se realizó antes del 28 de marzo cuando se inició la Semana Santa.

En las cornisas, dada su situación expuesta por ambas caras, se aplicó un tratamiento hidrofugante por su paramento trasero $y_{\text {, para }}$ evitar la acumulación de aguas sobre los paramentos, se resanaron las cubiertas y sistemas de desagües. En cuanto a la humedad capilar, se colocó en el muro una barrera por electroósmosis activa que, 

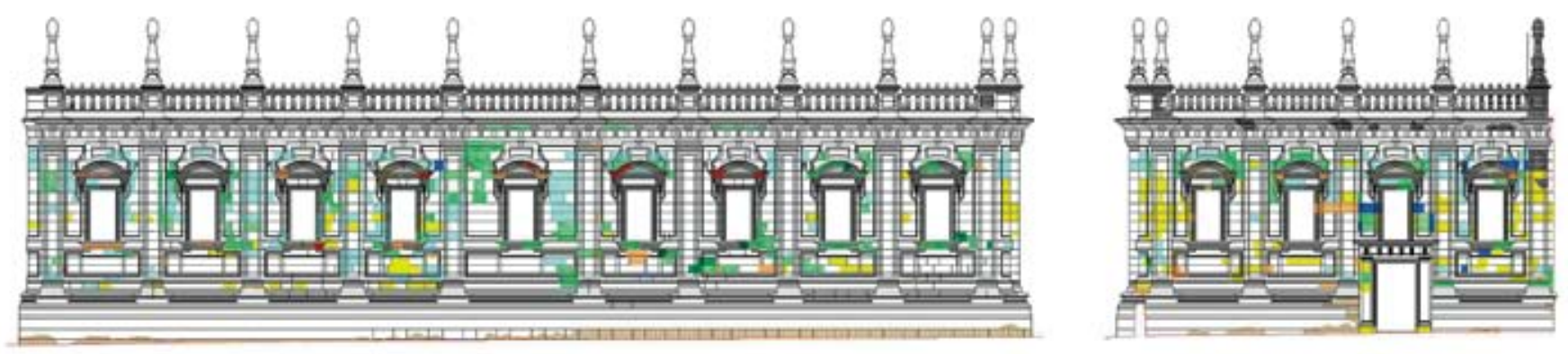

NaDosenticsase

ADROOBIF

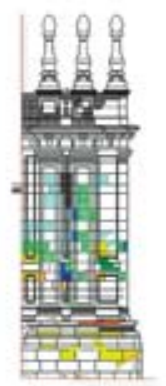

NZWDO CESTE NIETCO N

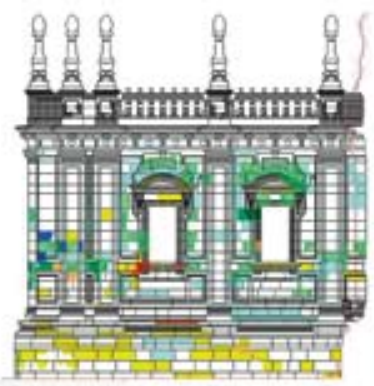

NEWO SUE POSTECCE

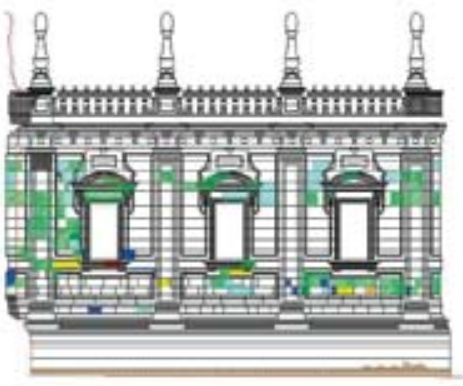

NZNOOCESE PUNCEN OO
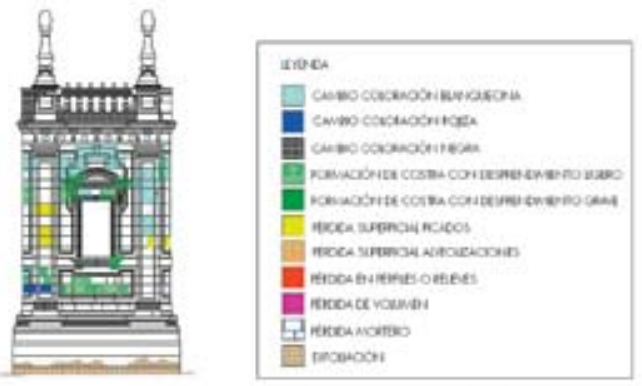

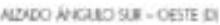

MAPAS DE DETERCROS APARENTES Y PERCIDAS DE MATERLLLL. ESTADO DE 2003.04

Mapa de deterioros aparentes y pérdida de material. Estado que presentaba la fachada. María Gracia Gómez de Terreros Guardiola y Carmen Enríquez Díaz, 2003-2004. Fuente: Representación elaborada a partir de la planimetría facilitada por Francisco Pinto Puerto

\section{Las variaciones y daños observados} en 2003 en el aspecto de la superficie pétrea motivaron el estudio de su comportamiento, iniciado con un mapa de alteraciones y un completo registro fotográfico

junto con el tratamiento superficial aplicado, parece haber mejorado el comportamiento de la piedra en la zona inferior del mismo.

\section{Tercera fase: actuación de terminación}

En julio-agosto de 2001, coincidiendo con la terminación de las obras del interior, se volvió a intervenir sobre la fachada del edificio, en un intento de reforzar la protección dada y lograr un aspecto más homogéneo de la superficie pétrea. Se intervino en un menor número de puntos, en los que se reintegraron algunos volúmenes con mortero pétreo Cumen como base y pigmentos minerales. Seguidamente, se consolidaron de nuevo ciertas zonas con Tegovakon, y se aplicó el hidrofugante Tegosivin a lo largo de toda la fachada, en la cantidad que absorbía la piedra. En las superficies de las fachadas del patio interior se aplicó el tratamiento general de esta tercera fase. En el interior sólo se aplicó el producto consolidante, al considerase que el hidrofugante no tenía sentido. En el tratamiento de las superficies interiores destacó la escasa absorción de las piedras, las cuales habian estado revestidas con sucesivas lechadas de cal durante muchos años.

\section{ANÁLISIS VISUAL EFECTUADO POCOS AÑOS DESPUÉS (2003-2006)}

A finales del año 2003 se observaron variaciones en el aspecto que presentaba la superficie pétrea y algunos daños, y esto fue lo que motivó el estudio de su comportamiento. La investigación se inició con la elaboración de un mapa de las alteraciones que se observaban en las fachadas y la realización de un completo registro fotográfico (GÓMEZ DE TERREROS, 2000: 19-28). El plano de las fachadas lo facilitó el arquitecto redactor del proyecto de intervención, Francisco Pinto Puerto, y, previamente al análisis y recogida de daños, se eliminó toda información sobre lesiones previas que éste recogía. Actuar de esta forma permitió iniciar el análisis de daños sin considerar las tipologias de lesiones anteriormente recogidas, ni tener referencia alguna sobre su situación y gravedad.

Tras la realización de este nuevo mapa se alteraciones se comparó con el que se había realizado previamente a la intervención. Se constataron cuatro cuestiones interesantes, que motivaron que se profundizase en el estudio de la intervención realizada. La primera surgió del análisis de las tipología de lesiones localizadas; la segunda, de su relación con las diferentes fases de la restauración; la tercera, de relacionar la situación de las lesiones con las previas a la intervención; $y$, finalmente, la cuarta, de relacionar la gravedad de las intervenciones puntuales y su estado de conservación posterior.

En lo que respecta a tipología de lesiones, las localizadas eran superficiales y de menor gravedad que las anteriores a la interven- 


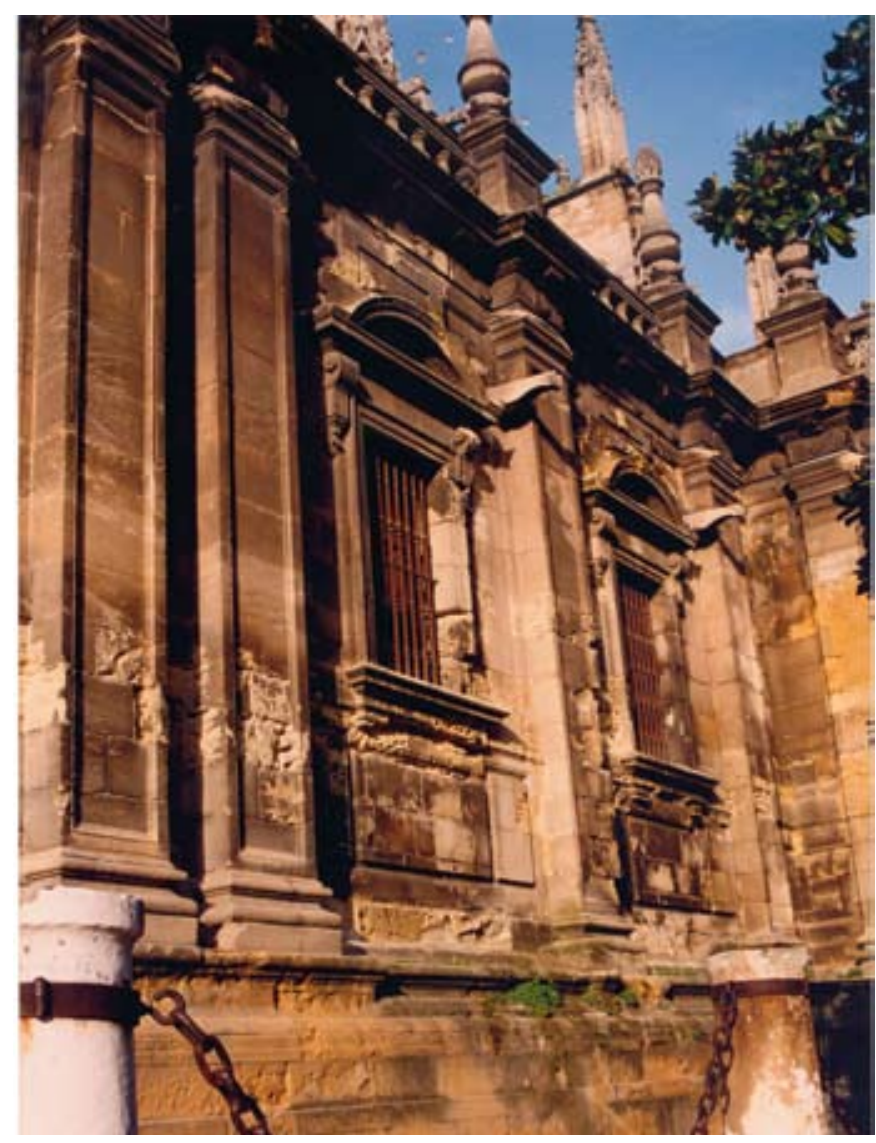

Estado de alteración que presentaba el módulo B de la fachada sur en 1996, con sillares que muestran importantes pérdidas de material, picados, descohesiones y bioalteraciones. Foto: Francisco Pinto Puerto

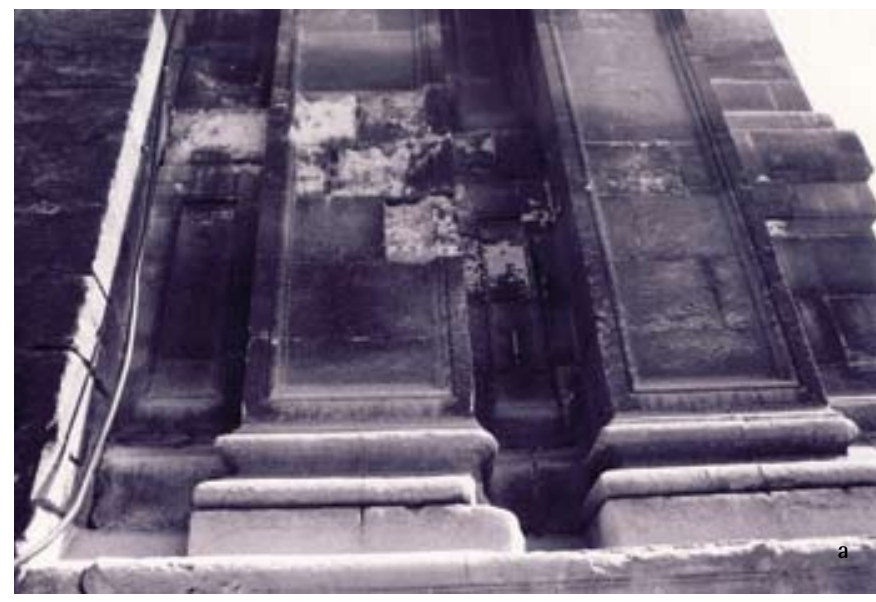

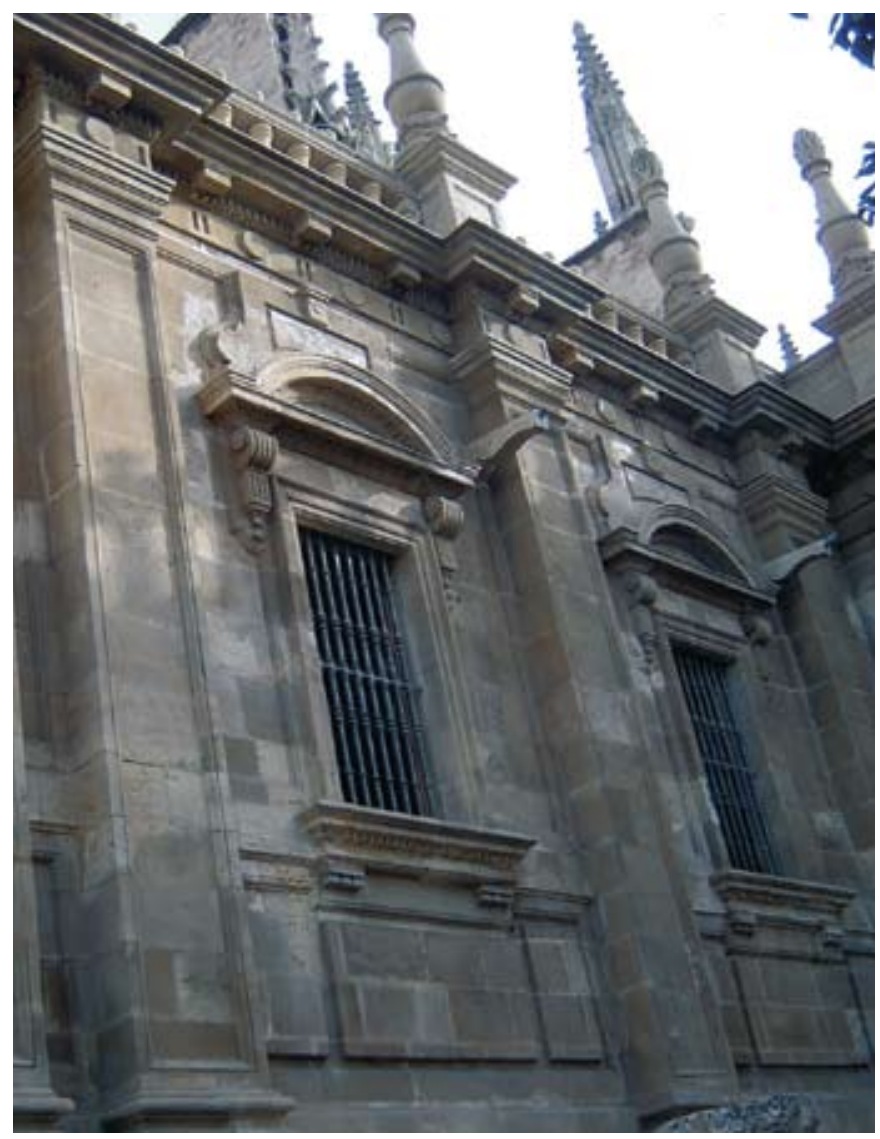

Estado de alteración que presentaba el módulo B de la fachada sur en 2004, donde aparecen lesiones de menor gravedad: variaciones en el aspecto, coloración superficial y ligeros picados. Foto: María Gracia Gómez de Terreros

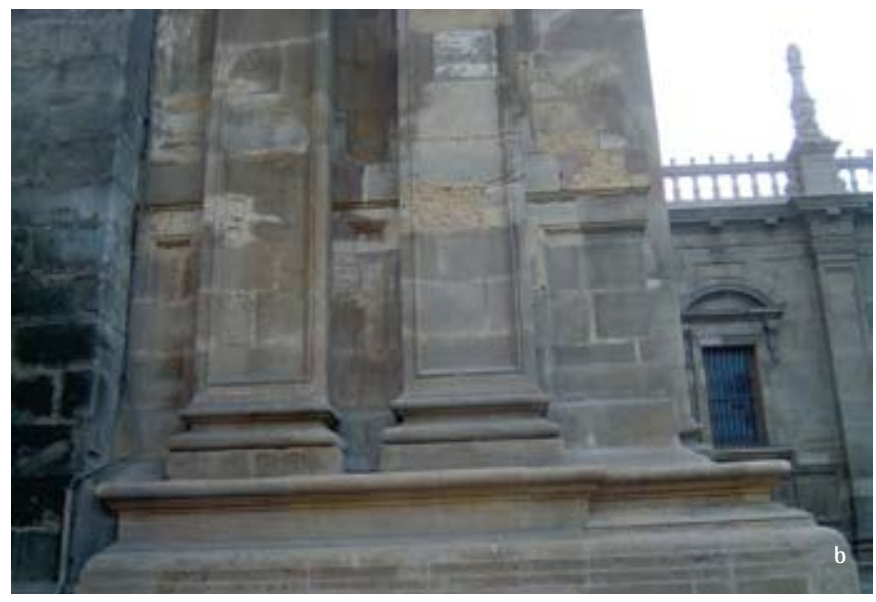

Estado de alteración de la zona de basamentos del módulo A de fachada oeste en 1988 (a) y en 2004 (b): Fotos: Manuel Alcalde Moreno (a) y María Gracia Gómez de Terreros (b)
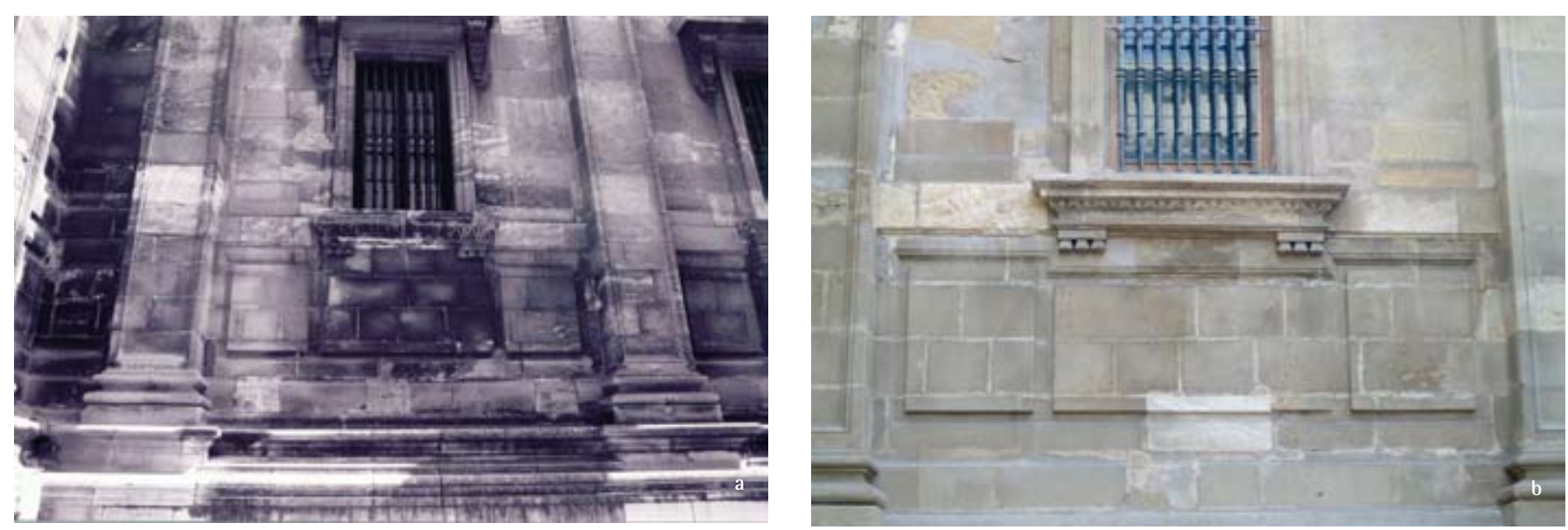

Estado de alteración que presentaba un módulo C3 de la fachada oeste en 1988 (a) y en 2004 (b). Fotos: M. Alcalde Moreno (a) y María Gracia Gómez de Terreros (b) 
ción. El primer análisis se realizó en diciembre de 2003; es decir, dos años y medio después de que se finalizase la intervención. Era una franja de tiempo muy reducida, por lo que planteaba dudas sobre la bondad de los tratamientos aplicados. El mapa de lesiones apreciadas previamente a la intervención recogía significativos cambios de coloración en la piedra debido a humedades (capilares y de filtración) e importantes faltas de material que se clasificaron por su importancia en falta de volúmenes, pérdidas superficiales, excoriaciones o faltas de material de juntas. Las fotografías anteriores a la intervención muestran la gravedad de las lesiones que presentaban algunos sillares y la urgencia de intervención que requerian (fundamentalmente las cornisas).

El mapa de lesiones posteriores apuntaba cambios de coloración y aspecto superficial, ligeras pérdidas de material y de morteros de juntas, puntuales formaciones de costras en distintas fases de desprendimiento, ligeros picados, alveolizaciones y exfoliaciones. La lesión más generalizada era un cambio del aspecto superficial de la piedra, tanto en su coloración como en su textura. Inicialmente se trataba de una cuestión estética de relativa importancia, pero que podria ir más allá en el futuro lo que a comportamiento de la superficie pétrea se refiere, y condicionar las decisiones a tomar en posteriores intervenciones. Se apreciaban dos tipos de variaciones superficiales: una, de tonalidad grisácea con una cierta apariencia viscosa, que genera una superficie continua o de aspecto de grano menos grueso; y otra, de ligera tonalidad rojiza pero de aspecto superficial más parecido a la piedra subyacente. Comparando fotografías de cuando se realizaron ambos análisis se aprecia que la gravedad de las lesiones localizadas antes de la intervención es mucho mayor que las posteriores.

Con referencia a las fases de la intervención, puede establecerse una relación entre las mismas y las tonalidades superficiales antes señaladas. Se han localizado fotografías fechadas que permiten apreciar cómo las variaciones de coloración guardan relación con la etapa en que se intervino. La tonalidad grisácea es más general y se aprecia desde la segunda fase de intervención, cuando se han aplicado los productos consolidantes e hidrófobos en la piedra. La tonalidad rojiza surge pasado un tiempo tras la tercera fase de intervención, cuando se aplica mortero de restauración en algunas superficies para igualar paramentos y aristas.

También la comparación en la situación de las lesiones resultaba interesante. Tras el análisis general, se realizó un despiece módulo a módulo, de forma que permitía concretar mucho mejor la localización de las lesiones y la comparación de entornos más inmediatos. Se apreciaba una coincidencia generalizada de variaciones en la situación de indicadores de alteración. Los sillares que previamente presentaban daños de mayor gravedad fueron sustituidos y reconstruidos sus volúmenes en la intervención, y son los que posteriormente presentan mejor estado de conservación. Contrastando con este hecho, los sillares situados en el entorno de los mismos sufren mayores alteraciones que las recogidas previamente a la intervención. Da la impresión de que frente a factores de alteración inamovibles, las variaciones realizadas en los sillares en la intervención han generado un nuevo estado de equilibrio piedra-entorno que se manifiesta a través de estos cambios superficiales apreciados. Al contar con algunas fotografias previas a la intervención, la veracidad de esta comparación realizada quedaba corroborada.

Finalmente, las intervenciones más drásticas o que pudieran considerarse más traumáticas, es decir aquellas en que los sillares se habian sustituido y otras donde se habian repuesto volúmenes, son los que actualmente presentan buen estado de conservación. Se destaca el comportamiento de los sillares sustituidos total o parcialmente, al igual que las reposiciones de volúmenes ornamentales. Ambos materiales poseen mejores características que la piedra original de la portada, a lo que hay que sumar que se colocaron sanos y sus superficies fueron tratadas como el resto de la fábrica.

\section{SEGUIMIENTO DEL ESTADO DE CONSERVACIÓN}

Las observaciones realizadas hicieron que se planteasen varias cuestiones sobre las lesiones que empezaban a manifestarse en la fachada: sus posibles causas, gravedad y cómo podrian evolucionar. También se planteó llevar un seguimiento del comportamiento de la piedra a lo largo del tiempo y, de este modo, tratar de comprobar la bondad de las soluciones llevadas a cabo en la misma a corto, medio y largo plazo. Se ha seguido durante más de tres años la evolución del estado de conservación de la fachada, y debe indicarse que el proceso de degradación superficial, que tan rápidamente se manifestó, parecía evolucionar más lentamente, ya que las variaciones eran casi inapreciables en algunos paramentos y no parecian haber evolucionado en otros. donde más se señalaba la evolución de lesiones era en las zonas donde éstas ya se presentaban con mayor rotundidad. Las cornisas mantenian el buen estado de conservación y apariencia, sin que se apreciara ninguna lesión. Y, en cuanto al zócalo general y la humedad capilar que tanto le afectaba hacía años, la barrera por electroósmosis activa colocada, junto con el tratamiento superficial aplicado, mejoraba el comportamiento de la piedra en esta zona, que mostraba escasas alteraciones superficiales.

\section{TOMA DE MUESTRAS, ENSAYOS Y OBSERVACIONES DE LABORATORIO}

El estudio de evolución de lesiones realizado daba una información valiosa, pero resultaba incompleta para poder establecer el acierto y/o la bondad o eficacia de la intervención realizada, tanto a corto como a largo plazo. Se planteó la realización de una serie de ensayos que permitieran, de alguna forma, entender el comportamiento de la piedra y su relación con los productos y tratamientos aplicados. Los ensayos fueron aportando una serie de datos que deben ser considerados en futuras intervenciones. 

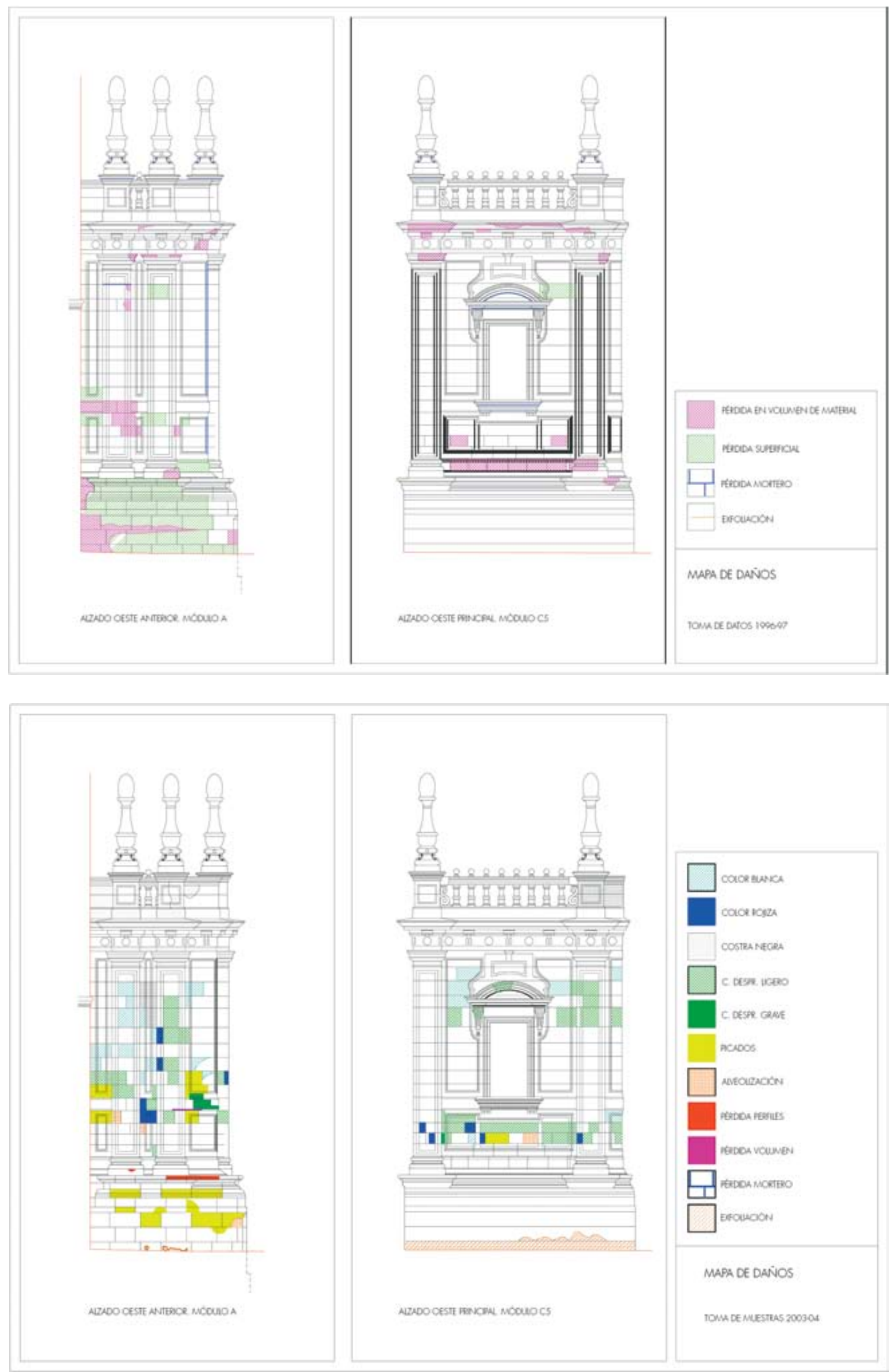

Mapas de lesiones de los módulos A y C5 de la fachada oeste de la Catedral realizados en distintas fechas, antes de la intervención y en 2004. María Gracia Gómez de Terreros y Carmen Enríquez Díaz. Fuente: Representación elaborada a partir de la planimetría facilitada por Francisco Pinto Puerto 

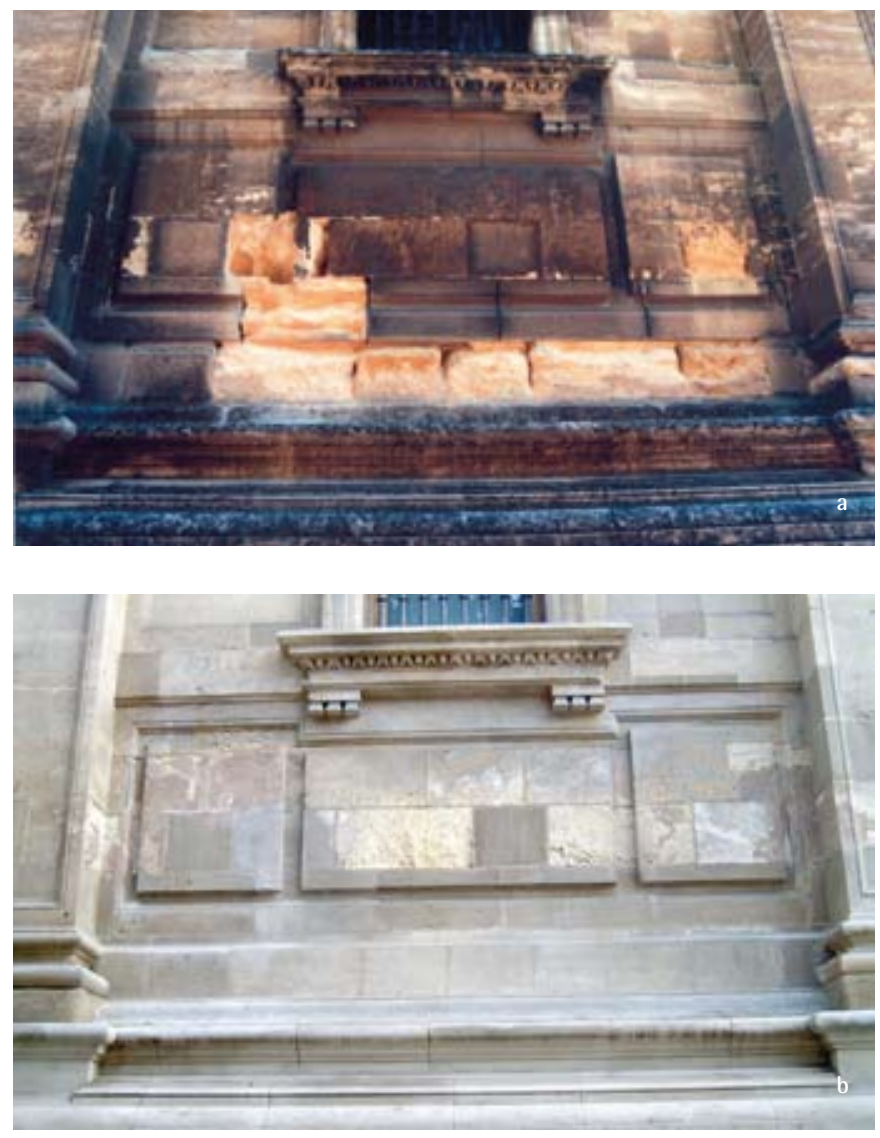

Estado de alteración del basamento del módulo $\mathrm{C} 5$ de la fachada oeste de la Catedral en 1988 (a) y en 2003 (b). Fołos: Manuel Alcalde Moreno (a) y María Gracia Gómez de Terreros (b)
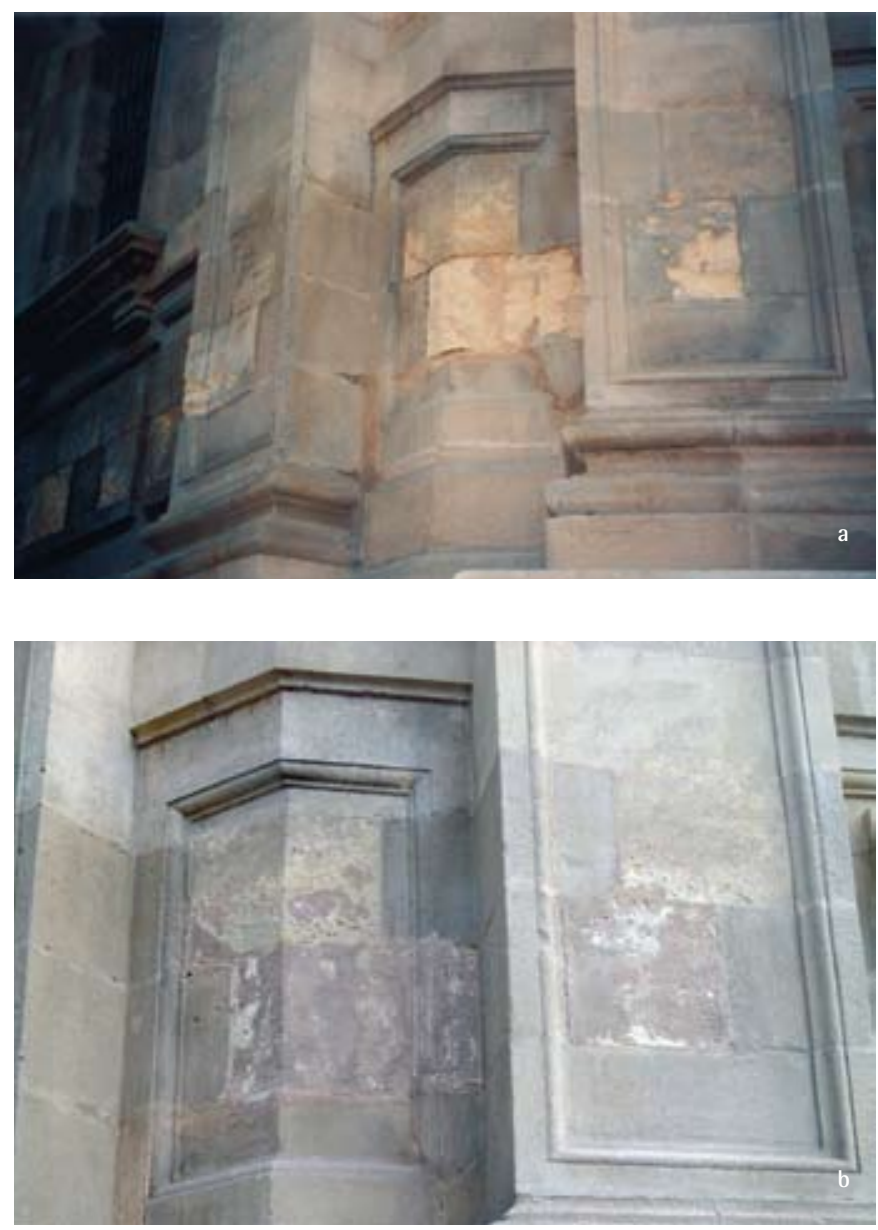

Detalle del estado que presentaba un paramento de la esquina de los módulos $C$ y D en 2001 (a), anterior a la tercera fase de intervención, y en 2003 (b).

Fotos: Carmen Enríquez Díaz (a) y María Gracia Gómez de Terreros (b)

\section{Toma de muestras}

Se tomaron varias muestras de piedra de la superficie de la fachada, todas ellas de costras que bien estaban desprendidas parcialmente, o bien que empezaban a manifestarse. Se han tomado de todas las fachadas, en la zona media (ni zócalo general ni cornisa), muestras de la superficie que presenta una coloración rojiza y de la que presenta un aspecto de diferente aspecto y coloración grisácea.

De cada una de las muestras se recogió su situación concreta y aspecto previo que presentaba y se conservó en bolsas y recipientes de material plástico, y por tanto estanco. Es de destacar la falta de resistencia o consistencia de la piedra, ya que la toma de muestras se llevó a cabo a mano, sin necesidad de utensilio o herramienta alguna. Bastaba forzar un poco la costra para que se desprendiera del resto de la fábrica. Incluso, en algunas zonas, se desprendia mucho más material del que se requería, sin que se pudiera evitar. Normalmente, tras la costra endurecida que se tomaba como muestra, la superficie de la piedra se presentaba aparentemente debilitada y/o decohesionada, y en algunos casos, con granos que se desprendian con facilidad, casi espontáneamente.

También debe señalarse la irregularidad en el espesor de las costras, y por tanto de las muestras obtenidas, hecho que puede considerarse propio o característico de un material irregular como es esta piedra calcarenita. Las costras son irregulares y varian de espesores que van a escasos milimetros a otros que cuentan con más de un centímetro de grosor. Los espesores de las muestras son independientes del aspecto o coloración superficial que presentase la piedra. El trasdós de todas las muestras tomadas tenian la apariencia de la piedra, en lo referente a coloración y aspecto superficial y las superficies que aparecian en los muros, tras las mismas, presentaban el mismo aspecto. El comportamiento que observamos en la piedra durante la toma de muestras, llevó a realizar una serie de ensayos, inicialmente muy sencillos, que aportaron cierta luz sobre la eficacia de la intervención, y que sucesivamente fueron llevando a a realizar otros más complejos, pero también más definitivos en sus resultados.

\section{Observaciones realizadas con el microscopio de campo y ensayo de gotas de agua}

Uno de los temas que más preocupaba determinar era si los tratamientos habian logrado penetrar suficientemente en la piedra, como para lograr consolidarla, o protegerla contra la humedad y el ambiente, y por tanto si eran eficaces (VILLEGAS, 1991: 1927). Se realizaron observaciones con el microscopio de campo y pudo apreciarse, en el intradós y en el trasdós de las muestras, cómo el tratamiento dado había rodeado los granos de la piedra. En las secciones transversales de las muestras se podia apreciar cómo todos los granos quedaban totalmente recubiertos por el mismo. El siguiente ensayo que se realizó fue el ensayo de go- 

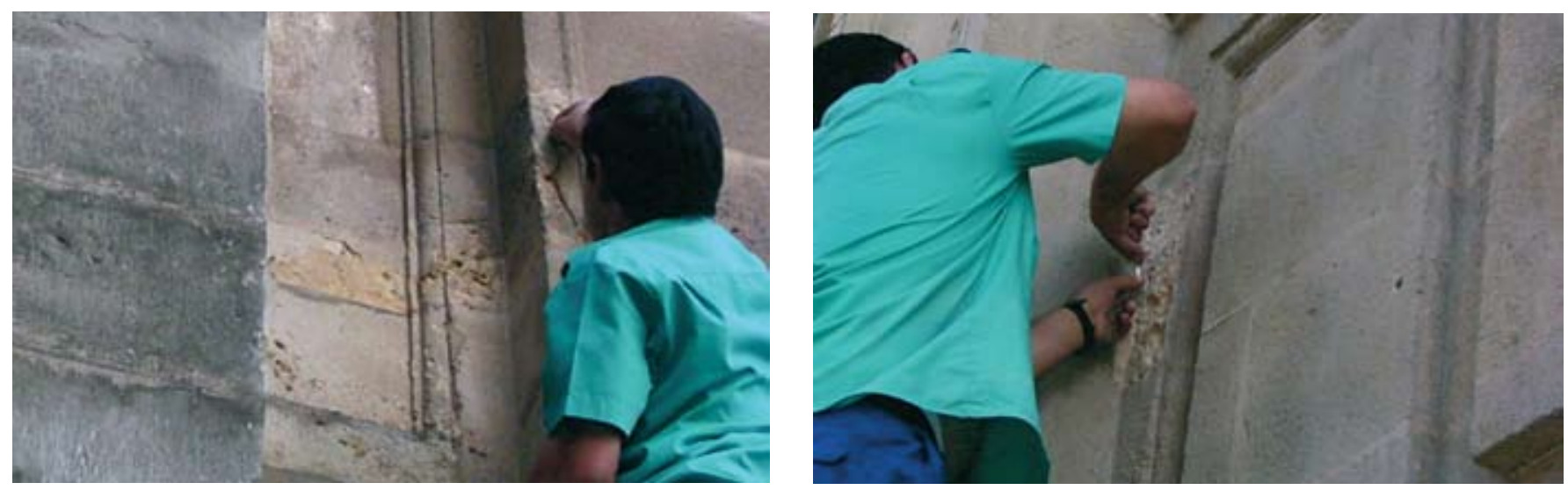

Imágenes de la toma de muestras en la fachada. Puede apreciarse la heterogeneidad en el espesor de las costras y el aspecto de la superficie pétrea sobre las mismas. Fotos: María Gracia Gómez de Terreros
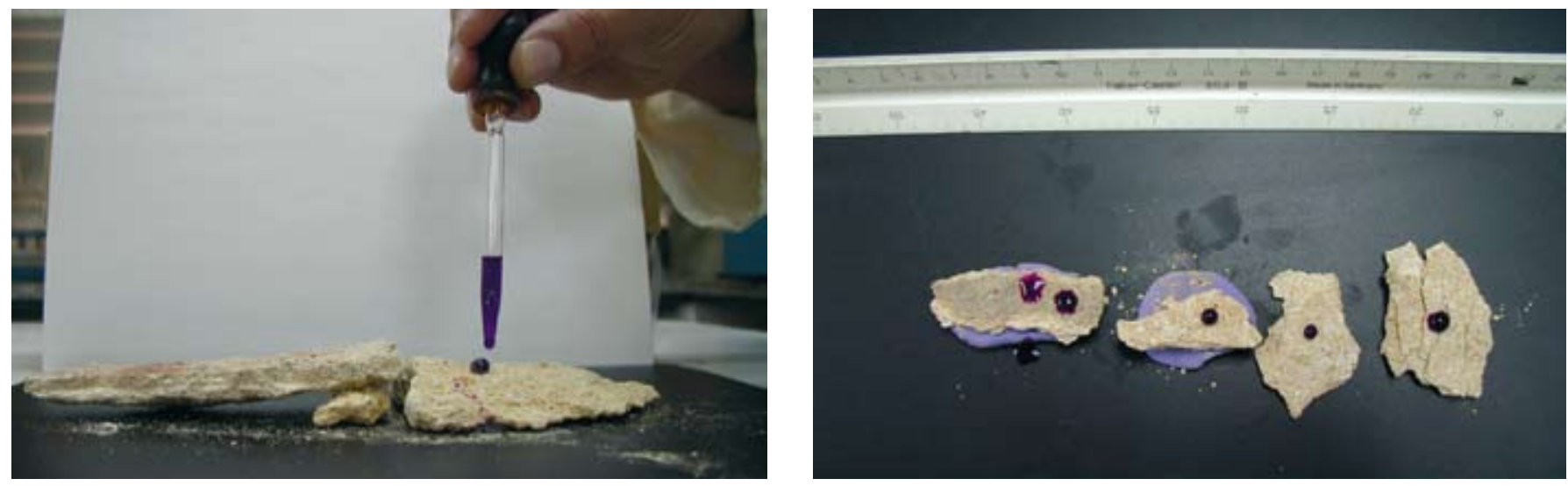

Imágenes del ensayo de gotas, donde todas las muestras se ensayaron por su intradós y su trasdós. Fotos: María Gracia Gómez de Terreros

tas. Todas las muestras tomadas se ensayaron por su intradós y por su trasdós, intentando comprobar si los tratamientos habian logrado cierta penetración y eficacia. Todas las muestras ensayadas repelieron el agua, generándose en muchas de ellas gotas con forma esférica.

El ensayo demostraba que se habían alcanzado profundidades suficientes para garantizar la protección de la piedra pretendida. La gran mayoría de las muestras mostraban mayor repelencia al agua por el trasdós de la muestras que por el frente o intradós. Esto nos indica que el tratamiento no ha perdido su eficacia global, aunque en la superficie haya podido sufrir cierto envejecimiento y degradación. Se destaca una de las muestras ensayadas, en que la piedra presentaba una desagregación general y con fisuraciones importantes en su trasdós, y en la que el tratamiento dado habia penetrado en las mismas ya que repelía el agua y formaba gotas esféricas en su superficie.

\section{Medidas de conductividad}

Otro aspecto de interés para el estudio realizado era comprobar la eficacia de la limpieza llevada a cabo en la intervención y/o la posible manifestación del inevitable ataque químico a la piedra por parte del ambiente contaminado donde está situada. Un ensayo muy sencillo de elaborar, que requería poco material y que podía dar indicios de contenidos de sales era la toma de medidas de conductividad. Se tomaron medidas de seis de las muestras, recogiendo material de la parte anterior y de la posterior de cada una de ellas, para observar posibles variaciones de contenidos. Se secaron las muestras a $60{ }^{\circ} \mathrm{C}$, se tomaron las cantidades a ensayar de cada una de ellas (entre 95 y $105 \mathrm{mg}$ ), se le añadieron $100 \mathrm{ml}$ de agua Milli- 0 , se voltearon durante 72 horas y se midió la conductividad a $25{ }^{\circ} \mathrm{C}$. La conductividad se expresó como $K=(a-b) / M$, siendo: $a$, conductividad de la muestras $\left(\mu \mathrm{S} . \mathrm{cm}^{-1}\right) ; b$, conductividad del agua $\left(\mu \mathrm{S} . \mathrm{cm}^{-1}\right)$; y $\mathrm{M}$, el peso de la muestra $(\mathrm{mg})$.

Se compararon los resultados del ensayo con los datos obtenidos en una investigación realizada hace varios años, por el investigador del Departamento de Química Analítica de la Universidad de Sevilla, doctor Miguel Ángel Bello López, sobre la caracterización química de la piedra de la Catedral de Sevilla y su alteración, e inicialmente se determinó que todas las muestras ensayadas contenían sales $e_{1}$ incluso, en algunas muestras en cantidades importantes (BELLO, 1988). En el estudio que desarrolló años atrás, el investigador señalaba que la alteración química que sufría la piedra de la Catedral de Sevilla se manifestaba a través de mayores contenidos en sulfato cálcico, con respecto a la piedra inalterada. Así pues, los resultados Ilevaron a plantear la posibilidad de evidenciar la bondad de la limpieza, o un rápido inicio en un nuevo proceso de alteración. Se cuestionó la realización de ensayos de caracterización química de la muestras, de 
componentes mayoritarios, aunque limitados a determinar los contenidos de $\mathrm{SO}_{3}$. Finalmente no fue necesario realizar este ensayo, ya que el microanálisis posteriormente realizado permitió obtener esta deseada información.

\section{Microanálisis y observaciones realizadas en el microscopio electrónico de barrido}

Se realizaron en el Servicio General de Microscopía del Centro de Investigación, Tecnología e Innovación de la Universidad de Sevilla (CITIUS) microanálisis a diez pequeñas porciones tomadas de cinco muestras (de su intradós y de su trasdós), utilizando un espectómetro de energía dispersiva (EDS), con una unidad DX4 de la marca EDAX, integrada en el microscopio electrónico de barrido (SEM), modelo XL30 de la marca PHILLIPS. Simultáneamente al microanálisis se observaron las superficies de las muestras en el microscopio electrónico de barrido, buscando posibles restos de sales y su posible identificación. Cinco observaciones pueden destacarse de los resultados del ensayo realizado. Algunas de ellas podrian plantear nuevas cuestiones a tratar, pero al ser ajenas al objetivo inicialmente propuesto, sólo se indican. En primer lugar, aparecieron pequeños contenidos de sulfato cálcico en el microanálisis de cuatro de las diez porciones ensayadas (dos corresponden al intradós y dos al trasdós de las muestras). Al cumplimentar estas informaciones con las observaciones realizadas en el microscopio electrónico de barrido, se apreció cómo se trataba de escasas formaciones de pequeños cristales de yeso (del orden de $0,2 \mu \mathrm{m})$ localizadas en el interior de poros.

\begin{tabular}{|l|c|c|c|}
\hline MUESTRA & PESO $(\mathrm{mg})$ & $\begin{array}{c}\text { CONDUCTIVIDAD } \\
\text { (Dato recogido) }\end{array}$ & $\begin{array}{c}\text { CONDUCTIVIDAD } \\
\text { (Dato corregido) K }\end{array}$ \\
\hline M1-Anterior & 103,3 & 106,0 & 102,3 \\
\hline M1-Posterior & 104,3 & 104,6 & 99,4 \\
\hline M2-Anterior & 98,4 & 372,0 & 377,1 \\
\hline M2-Posterior & 101,2 & 137,8 & 135,2 \\
\hline M5-Anterior & 101,1 & 209,0 & 205,8 \\
\hline M5-Posterior & 101,0 & 272,0 & 268,4 \\
\hline M8-Anterior & 99,1 & 225,0 & 226,1 \\
\hline M8-Posterior & 105,4 & 94,1 & 88,4 \\
\hline M9-Anterior & 101,8 & 103,6 & 100,8 \\
\hline M9-Posterior & 106,4 & 102,6 & 95,5 \\
\hline M14-Anterior & 102,4 & 85,9 & 83,0 \\
\hline M14-Posterior & 98,6 & 85,5 & 85,8 \\
\hline BLANCO & & 0,94 & \\
\hline
\end{tabular}

Tabla 1. Medidas de conductividad
Inicialmente sorprendió la presencia de cloruro sódico en la superficie del intradós o parte delantera de las dos muestras tomadas en el paramento más cercano a la avenida de la Constitución. En el microscopio electrónico de barrido se apreciaban formaciones de esta sal, que se presenta con formas cúbicas y también en pequeñas agujas y que, en algunas áreas, parece tapizar la superficie de la piedra. Son sales que surgen y se manifiestan con rapidez y no son agresivas para la piedra. Su origen puede ser debido tanto al contenido que porte o contenga la piedra como al ambiente de la ciudad, o del entorno. El lavado de la piedra puede facilitar su aparición.

En una muestra del intradós de la fachada principal aparecieron cristales de cloruro cálcico, compuesto que es más lógico, ya que la piedra tiene un alto porcentaje de carbonato cálcico. También resultaba curiosa la localización de pequeños contenidos de bario localizados en el trasdós de una de las muestras. Se apreciaban en el microscopio electrónico de barrido como cristales de un tamaño muy pequeño $(0,5 \mu \mathrm{m})$. Al ser un componente extrínseco a la piedra, puede tratarse de restos de algún tratamiento o ensayo del mismo llevado a cabo, o también puede ser debido a una contaminación puntual. Finalmente, en dos de las observaciones efectuadas se apreciaron roturas en el tratamiento, una corresponde al intradós y otra al trasdós. Lo cual podía ser indicador de que los productos pueden no haber sido aplicados con total eficacia. Podemos plantearnos dudas respecto al consolidante, pero el lo que al hidrofugante se refiere, el ensayo de las gotas de agua determina claramente su validez y eficacia.

\section{Medidas de color}

En la realización de algunos ensayos rutinarios de determinación de componentes mayoritarios, destacó que todas las muestras pulverizadas en el horno a una temperatura de $400{ }^{\circ} \mathrm{C}$ variaron su coloración, tornándose hacia una tonalidad rojiza oscura. Dado que el principal indicador de alteración de la piedra en la fachada se trataba de un cambio de aspecto y coloración, y que en determinadas zonas tomaba una tonalidad rojiza, se realizó un ensayo de color, combinado con variaciones de temperatura. También se planteó el realizar mediciones en el intradós y el trasdós de las muestras, ya que a simple vista se apreciaba una clara diferencia de coloración entre estas superficies.

Se realizaron medidas de color a temperatura ambiente, tras someterlas treinta minutos a un calentamiento de $80{ }^{\circ} \mathrm{C}$ y tras someterlas otros treinta minutos a $200{ }^{\circ} \mathrm{C}$. Las muestras se ensayaron por sus dos caras, comparando los resultados de las lecturas y también recogiendo las variaciones detectables a simple vista. Para la toma de lecturas se utilizaron dos colorimetros diferentes, dependiendo del tamaño de las muestras. Aquellas que podian contar con una superficie mayor a la que inscribiera una circunferencia de $2 \mathrm{~cm}$ de lado, se les efectuaron lecturas con un colorímetro Minolta CR-210, con iluminante CIE C. Se tomaron lecturas de ocho muestras. En las muestras que tenian un tamaño inferior 

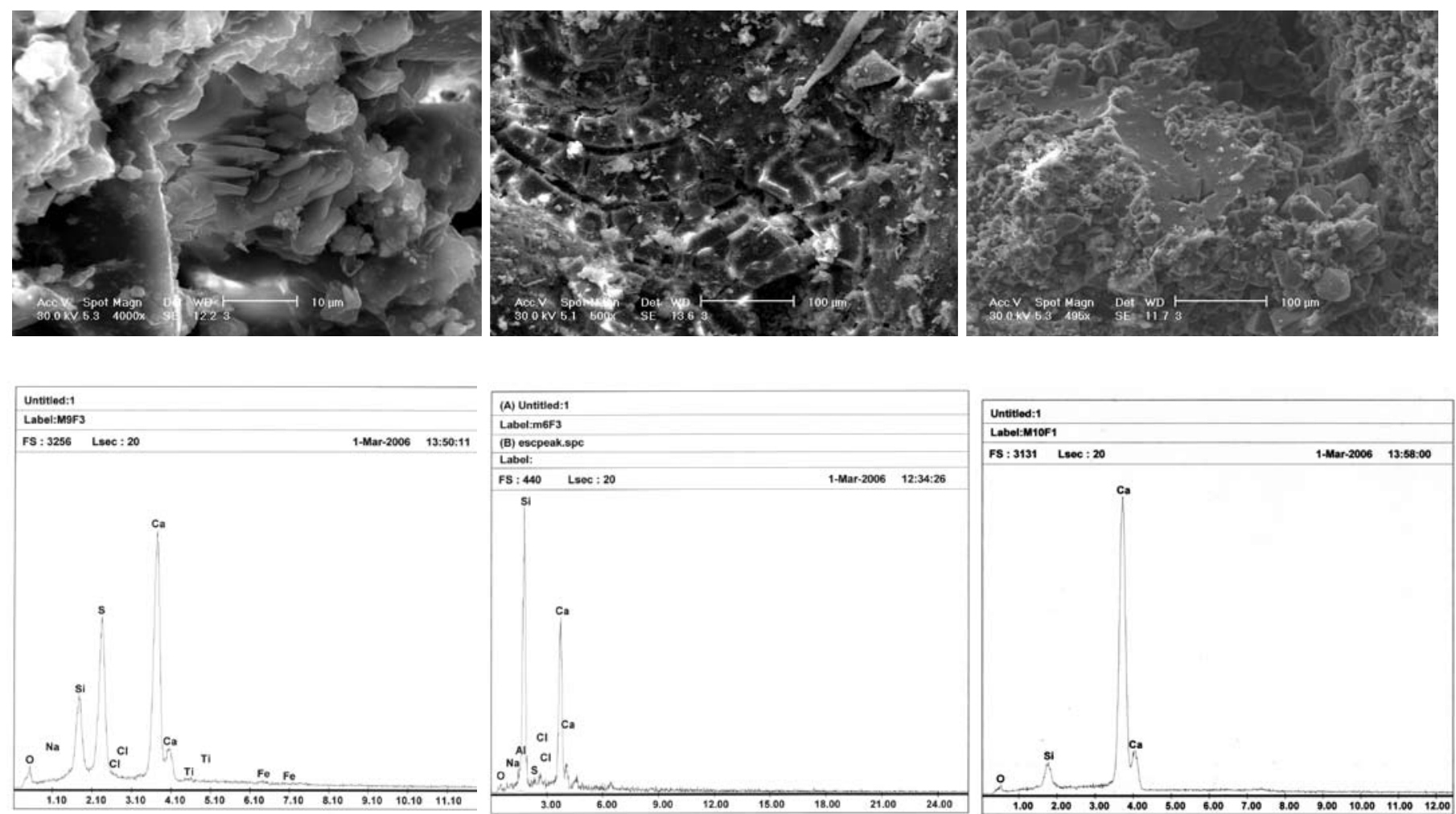

Foto de 4000 aumentos (S.E.M.) y gráfica de microanálisis. Muestra 14 (intradós). Se aprecian pequeñas formaciones de cristales de yeso en el interior de un poro. Fotos: María Gracia Gómez de Terreros
Foto de 500 aumentos (S.E.M.) y gráfica de microanálisis. Muestra 5 (trasdós). Se aprecia e agrietado del tratamiento que rodea la pétrea. Fotos: María Gracia Gómez de Terreros
Foto de 500 aumentos (S.E.M.) y gráfica de microanálisis. Muestra 14 (trasdós). Se aprecian cristales de calcita del cementante de la piedra. Fotos: María Gracia Gómez de Terreros se utilizó, para efectuar las lecturas un color-pen universal de la marca DR Lange, con botón de medida LZM 163, Standard \# 9640. Se tomaron lecturas de cinco muestras. Se realizaron tres medidas en cada lectura y se adoptó la media de los valores obtenidos.

A simple vista, todas las muestras presentaban su cara exterior con un aspecto más oscurecido y en laboratorio la tonalidad rojiza parecia matizada. La comparación de los resultados obtenidos corroboraban estas observaciones. Salvo alguna excepción, todas las muestras presentaban mayores valores de luminosidad por su trasdós. De forma similar ocurría con el valor "b" de la lectura efectuada. Por el contrario, el valor "a" oscilaba, aumentando en algunos valores y disminuyendo en otros. Las lecturas efectuadas no marcan ni señalan las diferencias de tonalidad que parecian apreciarse en la superficie de la fachada. Los valores de las costras de tonalidad rojiza oscilan de forma similar a las grisáceas. Finalmente, los resultados obtenidos en las lecturas efectuadas no daban indicación alguna de variaciones de color debidas al comportamiento térmico de las muestras en ninguna de sus caras. Al tener algunos de los productos aplicados de cierta naturaleza orgánica, las temperaturas de $200{ }^{\circ} \mathrm{C}$ podrian afectarles de alguna forma pero el color de sus superficies no se ha visto afectado.

\section{CONCLUSIONES}

El resultado de la intervención llevada a cabo fue satisfactorio inicialmente. La construcción presentaba buen estado de conservación, con una imagen acorde con el paso del tiempo y distante de la de un edificio nuevo. Las soluciones más drásticas, adoptadas en elementos como cornisas y salientes, permitian recuperar aspectos tan fundamentales como son la seguridad de viandantes y la estabilidad de la propia fábrica, quedando además perfectamente integradas en el monumento. La aplicación de los tratamientos previamente ensayados pareció en un principio acertada y adecuada, sin que se apreciasen ningún tipo de incompatibilidad o comportamiento anómalo. El aspecto y resistencia de la piedra en superficie mejoraba, al igual que su comportamiento hidrófobo. El aspecto de su superficie no sufrió variaciones, si bien se aplicaron pátinas en forma de veladuras de restauración que trataban de dar uniformidad al conjunto de la fábrica. La intervención frenó el progresivo deterioro en que se encontraba la piedra, y generó una correcta estrategia de conservación, al realizar un profundo análisis del estado de alteración previo y aportar datos concretos y localizaciones de las distintas soluciones dadas.

A partir de las observaciones realizadas pocos años después y de los resultados de los ensayos llevados a cabo, pueden darse una serie de conclusiones sobre la intervención realizada que, como era previsible, cuenta con medidas que a medio plazo parecen acertadas, y otras que deberán ser consideradas cara a futuras intervenciones. La limpieza llevada a cabo en la superficie de la piedra ha sido acertada, tanto en su aspecto macroscópico como en el microscópico. La superficie pétrea cuenta con una pátina de envejecimiento, cuyas costras oscurecidas quedan lejos de ser derivadas de su reacción con el ambiente contaminado del entorno. Contrastan especialmente las zonas de cornisas y zócalos que anteriormente presentaban un oscurecimiento generalizado. A nivel 

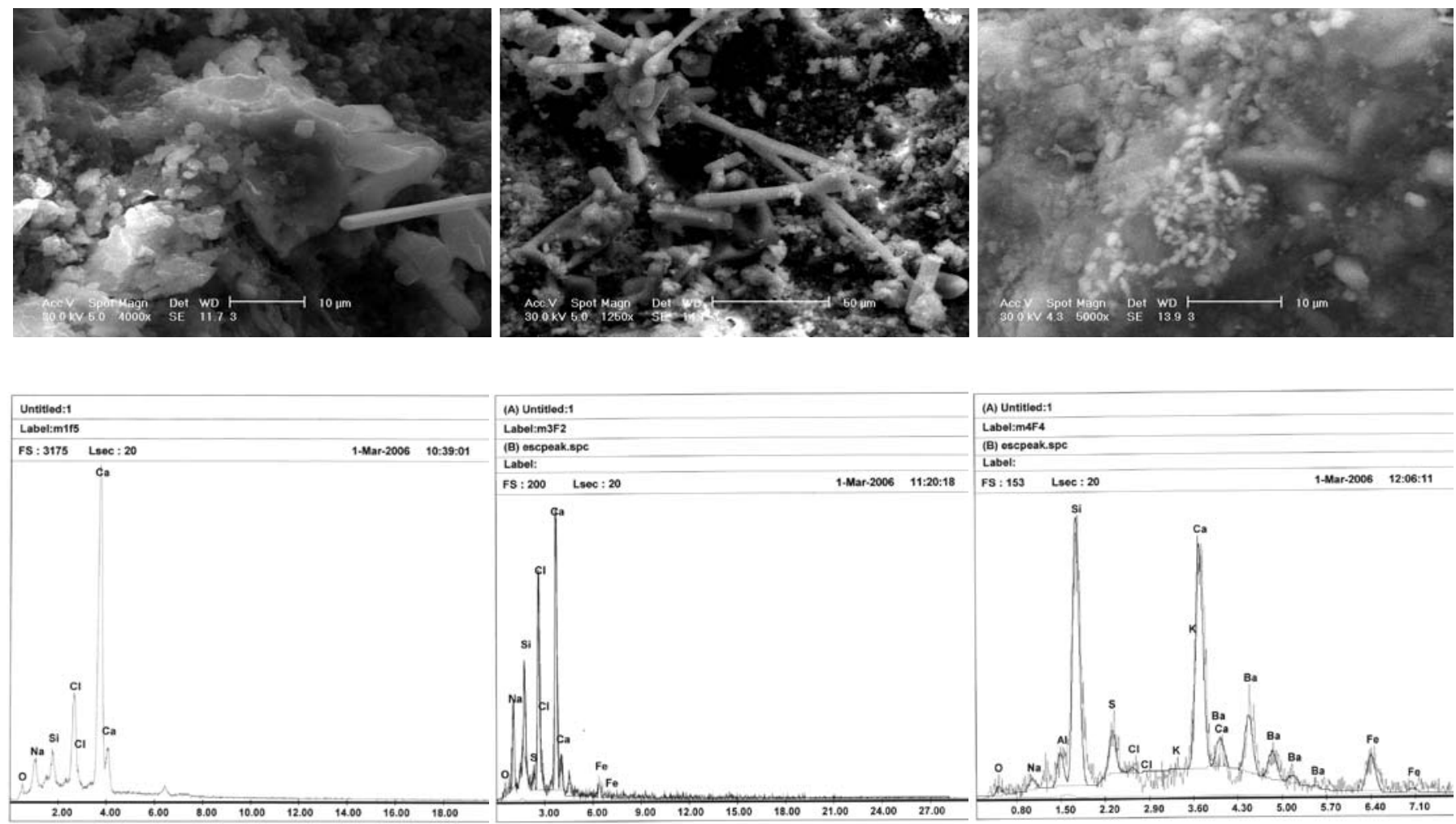

Foto de 4000 aumentos (S.E.M.) y gráfica de microanálisis. Muestra 1 (intrasdós). Se aprecian pequeñas formaciones de cristales de cloruro cálcico.

Fołos: María Gracia Gómez de Terreros
Foto de 1250 aumentos (S.E.M.) y gráfica de microanálisis. Muestra 2 (intrasdós). Se aprecian pequeñas formaciones de cristales de cloruro sódico. Fotos: María Gracia Gómez de Terreros

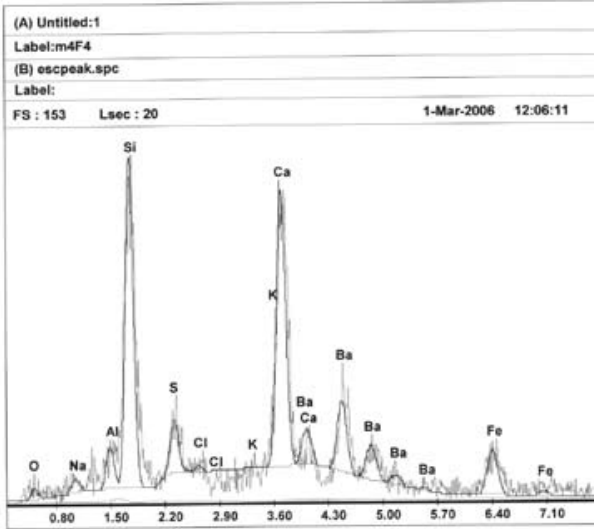

Foto de 5000 aumentos (S.E.M.) y gráfica de microanálisis. Muestra 2 (trasdós). Se aprecian pequeños contenidos de bario.

Fołos: María Gracia Gómez de Terreros

\begin{tabular}{|c|c|c|c|c|c|c|c|c|c|c|c|c|c|c|c|}
\hline & \multicolumn{3}{|c|}{ A T ambiente } & \multicolumn{3}{|c|}{30 min a $80{ }^{\circ} \mathrm{C}$} & \multicolumn{3}{|c|}{30 min a $200^{\circ} \mathrm{C}$} & \multicolumn{2}{|c|}{ Dif. Amb. $-80{ }^{\circ} \mathrm{C}$} & \multicolumn{2}{|c|}{ Dif. Amb. $-200{ }^{\circ} \mathrm{C}$} & \multicolumn{2}{|c|}{ Dif. $80^{\circ} \mathrm{C}-200^{\circ} \mathrm{C}$} \\
\hline & $L^{*}$ & $a^{*}$ & $b^{*}$ & $L^{*}$ & $a^{*}$ & $b^{*}$ & $L^{*}$ & $A^{*}$ & $b^{*}$ & $\mathrm{E}$ & C & $\mathrm{E}$ & C & $\mathrm{E}$ & C \\
\hline $\mathrm{P} 2 \mathrm{a}$ & 55,20 & 1,55 & 12,28 & 59,06 & 4,97 & 12,19 & 58,02 & 2,90 & 12,60 & 5,1540 & 3,4211 & 3,1380 & 1,3884 & 2,3526 & 2,1099 \\
\hline $\mathrm{P} 2 \mathrm{~b}$ & 71,84 & 4,33 & 27,98 & 69,37 & 2,27 & 16,36 & 68,91 & 6,17 & 23,04 & 12,0647 & 11,8108 & 6,0341 & 5,2742 & 7,7578 & 7,7436 \\
\hline $\mathrm{P} 4 \mathrm{a}$ & 59,04 & 2,49 & 11,96 & 63,09 & 2,32 & 11,00 & 61,69 & 2,95 & 10,12 & 4,1581 & 0,9788 & 3,2594 & 1,8967 & 1,7616 & 1,0815 \\
\hline $\mathrm{P} 5 \mathrm{~b}$ & 68,67 & 3,93 & 17,17 & 74,95 & 3,04 & 15,62 & 71,56 & 3,91 & 14,90 & 6,5269 & 1,7814 & 3,6739 & 2,2687 & 3,5746 & 1,1357 \\
\hline $\mathrm{P} 3 \mathrm{a}$ & 49,37 & 4,07 & 16,37 & 51,00 & 4,23 & 17,70 & 49,53 & 4,97 & 15,40 & 2,1098 & 1,3396 & 1,3329 & 1,3232 & 2,8282 & 2,4161 \\
\hline P3b & 60,90 & 6,40 & 28,33 & 60,57 & 6,67 & 27,93 & 59,03 & 7,20 & 27,50 & 0,5846 & 0,4826 & 2,1968 & 1,1528 & 1,6845 & 0,6825 \\
\hline $\mathrm{P} 8 \mathrm{a}$ & 60,93 & 4,87 & 14,07 & 61,77 & 4,87 & 14,43 & 60,83 & 6,00 & 15,33 & 0,9139 & 0,3600 & 1,6954 & 1,6925 & 1,7235 & 1,4446 \\
\hline P8b & 73,20 & 2,23 & 17,33 & 74,53 & 2,33 & 17,90 & 75,43 & 2,77 & 17,33 & 1,4504 & 0,5787 & 2,2944 & 0,5400 & 1,1526 & 0,7201 \\
\hline $\mathrm{PQa}$ & 65,37 & 1,87 & 14,17 & 67,40 & 1,90 & 14,40 & 66,93 & 2,93 & 13,87 & 2,0432 & 0,2319 & 1,9098 & 1,1016 & 1,2501 & 1,1584 \\
\hline $\mathrm{P} 9 \mathrm{~b}$ & 69,17 & 4,53 & 22,30 & 70,43 & 4,60 & 22,20 & 71,10 & 5,27 & 23,53 & 1,2659 & 0,1221 & 2,4053 & 1,4354 & 1,6330 & 1,4892 \\
\hline PlOa & 65,80 & 4,83 & 17,03 & 63,43 & 4,63 & 16,43 & 66,43 & 5,10 & 16,80 & 2,4529 & 0,6325 & 0,7230 & 0,3547 & 3,0591 & 0,5982 \\
\hline PlOb & 69,60 & 2,13 & 13,93 & 68,00 & 2,10 & 13,80 & 69,87 & 2,43 & 15,13 & 1,6056 & 0,1334 & 1,2661 & 1,2369 & 2,3183 & 1,3703 \\
\hline Plla & 74,33 & 1,63 & 14,93 & 73,10 & 2,07 & 15,47 & 73,37 & 2,07 & 16,70 & 1,4135 & 0,6966 & 2,0611 & 1,8239 & 1,2593 & 1,2300 \\
\hline P1 lb & 69,37 & 4,53 & 21,13 & 70,70 & 4,50 & 20,70 & 71,77 & 5,63 & 22,27 & 1,3981 & 0,4310 & 2,8757 & 1,5842 & 2,2106 & 1,9344 \\
\hline
\end{tabular}


microscópico, la eficacia de la limpieza queda demostrada por la falta de sulfatos en su superficie, que se reducian a formaciones muy pequeñas de cristales de yeso en el interior de poros.

Las aplicaciones dadas de productos consolidantes e hidrófobos han tenido un comportamiento que parece variar en el tiempo. A medio plazo, la superficie de la piedra sufre las alteraciones en su aspecto y coloración que ya han sido descritas. En la toma de muestras efectuada se observó cómo en la piedra se han formando costras de material consolidado, de irregular espesor, tras las cuales el material aparecía decohesionado. Este comportamiento es característico del tipo de material pétreo del que se trata, con lo que la eficacia del sistema piedra alterada-producto consolidante es inferior a lo deseado. A través del ensayo de gotas, sí quedaba demostrada la eficacia del producto hidrófobo utilizado.

La última fase de la intervención realizada, en la que se volvieron a repetir las aplicaciones de productos, y se realizaron reposiciones superficiales con mortero de reparación Cumen, es la que a medio plazo presenta los daños más destacables, con una variación de color que se aprecia a simple vista y con formación de costras que se separan y se desprenden pocos años después de su aplicación.

Las sustituciones y reposiciones llevadas a cabo parecen muy acertadas, tanto en sus soluciones técnicas, como en los materiales utilizados y las dimensiones dadas a los mismos. Las zonas de cornisas destacan en su aspecto, que mantiene la apariencia de la fachada recién restaurada. Las superficies de zócalos sustituidas también presentan un perfecto estado de conservación, que a veces contrasta con el estado de la piedra original. Las soluciones técnicas de apoyo para evitar la humedad en el interior de la piedra, como son la aplicación de un revestido por el trasdós de la cornisa y la colocación de la barrera electroosmótica frente a la humedad capilar, con seguridad, han colaborado al éxito de estas soluciones.

La comparación entre los mappings de indicadores de alteración, previo y unos años posteriores a la intervención, muestran unas significativas coincidencias en las localizaciones de daños. Los sillares en los que más se ha intervenido mantienen el aspecto de recién restaurados. Por el contrario, el entorno de los mismos sufre alteraciones de mayor intensidad que antes de la restauración. Asi pues, el sistema de equilibrio piedra-entorno que llevó a la fachada a necesitar una intervención de cierta urgencia se ha visto modificado y, con el paso del tiempo se puede apreciar cómo se va generando de nuevo, manifestándose similarmente al estado anterior, y con caracteristicas de alteración que le son propias a la piedra. Como conclusión final debe indicarse que el estudio realizado demuestra que toda piedra de escasa resistencia y cohesión entre sus granos naturales (podria definirse de relativa baja calidad para la construcción) que esté degradada, si puede mejorar en su aspecto y comportamiento superficial a corto plazo mediante la aplicación de tratamientos superficiales; pero a medio o largo plazo su comportamiento vuelve a ser propio y característico de ella misma y del equilibrio que mantiene con su entorno.

\section{Agradecimientos}

Al Cabildo de la Santa Iglesia Metropolitana Hispalense, al maestro mayor de obras de la Catedral de Sevilla, D. Alfonso Jiménez Martín, a los arquitectos autores del proyecto, D. Francisco Pinto Puerto y D. Miguel Ángel Som Ruiz, y a los profesores de la Universidad Hispalense D. Manuel Alcalde Moreno, D. Miguel Ángel Bello López y Da Rosario Villegas Sánchez.

\section{Bibliografía}

ALCALDE, M.; MARTíN A. (1990) Morfología macroscópica de alteración de la piedra de la Catedral de Sevilla, España. Mater Construcc, vol. 40, n² 219, 1990, pp. 5-28

BELLO LOPEZ, M. Á. (1988) Caracterización y estado de alteración química de los materiales empleados en la construcción de la Catedral de Sevilla. Tesis doctoral. Universidad de Sevilla, 1988

ESBERT, R. M. ET ÁL. (1988) Caracterización petrofísica y alterabilidad de las piedras de la Catedral de Sevilla. Mater Contrucc, vol. 38, n² 210, 1988, pp. 5-23 GÓMEZ DE TERREROS GUARDIOLA, M. G.; ALCALDE MORENO, M. (2000) Metodología de estudio de la alteración y conservación de la piedra monumental. Sevilla : Universidad de Sevilla, Secretariado de Publicaciones, 2000, 93 p. GÓMEZ DE TERREROS GUARDIOLA, M. V. (1993) Obras de restauración y terminación de la fachada del ángulo suroeste de la Catedral de Sevilla. El proyecto de Francisco Javier de Luque. Laboratorio de Arte, 6, 1993, p. 250 GÓMEZ DE TERREROS GUARDIOLA, M. V. (1996) Obras de Joaquin de la Concha Alcalde en la Catedral de Sevilla. Laboratorio de Arte, 9, 1996, pp. 209-238 JIMÉNEZ MARTÍN, A.; PINTO PUERTO, F. (2003) Levantamiento y análisis de edificios. Tradición y futuro. Sevilla : Secretariado de Publicaciones, Universidad de Sevilla, Instituto Universitario de Ciencias de la Construcción, 2003, pp. 183-223 VILLEGAS, R.; VALE, F. J.; ALCALDE, M. (1991) Evaluación de tratamientos de hidrofugación aplicados a piedras calizas de Catedrales Andaluzas. Mater Contrucc, vol. 41, n²23, 1991, pp. 19-27

VILLEGAS, R.; VALE, F. J. (1993) Evaluación de tratamientos de hidrofugación aplicados a piedras calizas de Catedrales Andaluzas. II. Ensayo de cristalización de sales. Mater Contrucc, vol. 43, n² 230, 1993, pp. 5-13

VILLEGAS, R.; VALE, F. J. (1993) Evaluación de tratamientos de hidrofugación aplicados a piedras calizas de Catedrales Andaluzas. III Ensayo de alteración acelerada en atmósfera contaminada. Mater Contrucc, vol. 43, n²32, 1993, pp. 25-37 